\title{
Las elecciones del Frente Popular en la provincia de Alicante
}

The Popular Front Elections in the province of Alicante

\author{
Juan Martínez Leal \\ IES Figueras Pacheco de Alicante
}

Recibido: 20-III-2012

Aceptado: 27-XI-2012

\section{Resumen}

Las elecciones del Frente Popular fueron las últimas y más decisivas realizadas durante la Segunda República Española. Confrontados los españoles en dos grandes bloques electorales, estas elecciones se vivieron con una especial intensidad en la provincia de Alicante, donde la República había echado hondas raíces, especialmente en los pueblos industriales y en la capital. Por primera vez, en base al Acta del Escrutinio Oficial de la Junta del Censo Electoral Provincial se recogen los resultados ordenados pueblo a pueblo para componer un completo mapa electoral de toda la provincia. El Frente Popular venció en los comicios de forma clara pero ajustada y, sobre todo, de forma limpia y democrática.

Palabras clave: Frente Popular, Elecciones, Segunda República, Alicante, Revolución, Contrarrevolución, Fascismo, Socialismo, Anarquismo.

\begin{abstract}
The Popular Front elections were the last and most critical one made during the Second Spanish Republic. Confronted the Spanish in two major electoral blocks, these elections were experienced with particular intensity in the province of Alicante, where the Republic had taken deep roots, especially in the industrial towns and in the capital. For the first time, according to the official canvass of the Provincial Electoral Board, results on scrutiny of votes are sorted out by town in order to compose a comprehensive electoral map of the whole province. The Popular Front won the elections in a clear but tight manner, although, above all, it was a democratic and clean process.
\end{abstract}

Keywords: Popular Front, Elections, Second Republic, Alicante, Revolution, Counterrevolution, Fascism, Socialism, Anarchism. 
"Las pasiones políticas, el genio literario, la vitalidad cultural, el idealismo individual, la generosidad de todas las clases españolas estaban en pleno apogeo en el año 1935".

Gabriel Jackson, La República española y la guerra civil (1976)

\section{Introducción}

De las elecciones generales de nuestra historia, las del 16 de febrero de 1936, conocidas como del Frente Popular, han sido probablemente las más decisivas y las más controvertidas, también en el ámbito historiográfico. Desde los ya lejanos y pioneros estudios de Javier Tusell y Juan J. Linz ${ }^{1}$, de la década de los setenta del pasado siglo, han ido proliferando los estudios locales y en menor medida los provinciales, importantes pero todavía fragmentarios, si tenemos en cuenta que la provincia salvo muy pocas excepciones coincidía con el distrito electoral ${ }^{2}$. Un estudio sistemático de las fuentes electorales a escala de distritos-provincia, nos acercaría a la diversidad, aportando clave sociológicas del voto ciudadano, pero también ayudaría a recomponer con mayor precisión los resultados nacionales (por agregación y comparación de datos), aportando una visión más profunda de cómo votaron los españoles en aquella crucial coyuntura. En este empeño se enmarca este trabajo.

La dificultad de la empresa no es poca y entre las razones habría que señalar las derivadas de la complejidad del sistema electoral republicano, pero también de la magnitud, la dificultad de acceso y del manejo de la dispersa documentación de los distritos electorales, si bien los resultados de los escrutinios oficiales fueron publicados en la prensa. Para dar una idea de tal dificultad, los estudios más ambiciosos y clásicos, especialmente el de Javier Tusell se decantan por presentar los resultados a partir de la suma aritmética del candidato más votado en cada circunscripción, ni siquiera de los votos obtenidos por la candidatura completa, que coincidía con los escaños asignados a las mayorías. Nada digamos de las discrepancias en torno a la forma de presentar los resultados,

1. TUSELL, Javier, Las elecciones del Frente Popular, 2 tomos, Madrid, Cuadernos para el Diálogo, 1971. LINZ, Juan J., DE MIGUEL, Jesús, "Hacia un análisis regional de las elecciones de 1936 en España", Revista Española de Opinión Pública, no 48 (1977), pp. 27-68.

2. El más reciente y exhaustivo estudio sobre las elecciones en la República se centra, sin embargo, en las elecciones de 1933. VILLA, Roberto, La República en las urnas. El despertar de la democracia en España, Madrid, Marcial Pons, 2011. En sus referencias bibliográficas hay una buena recopilación de los estudios electorales en el periodo republicano, lo cual sería imposible en el marco de este trabajo. Para los estudios electorales sobre el periodo también puede consultarse, aunque queda más lejana su publicación: MATEOS RODRÍGUEZ, Miguel Ángel, "Fuentes y metodología para el estudio electoral de la II República española", Ayer, no 3 (1991), pp. 139-164. 
agrupando o reagrupando los datos en función de criterios derecha-centroizquierda, en el complicado mapa partidista e ideológico de la época. Todo ello, en unos comicios donde fue predominante la confrontación de coaliciones, de bloques político-ideológicos. Por último, señalemos las propias vicisitudes del proceso electoral, especialmente para los casos donde hubo que ir a segunda vuelta, bien por la propia mecánica de la ley o por la impugnación de actas en las nuevas Cortes. En estos casos, las excepcionales circunstancias políticas que concurrieron, han alimentado prácticamente hasta nuestros días las polémicas acerca de la mayor o menor legitimidad de los resultados.

En el caso del estudio electoral de la provincia de Alicante ${ }^{3}$, abundan las fuentes de primera mano para componer el cuadro electoral pueblo a pueblo, comarca a comarca, pero la extracción de datos, ordenación, clasificación y escrutinio es de un volumen que puede llegar a rebasar el trabajo individual, haciéndose absolutamente necesario contar con los debidos soportes informáticos.

Adelantemos que en el caso alicantino nunca se discutieron los resultados finales, ni en los primeros días durante el escrutinio oficial ni en la Comisión de Actas de las Cortes, por lo que no se trata tanto de la cuestión de la validez o legitimidad de los resultados, como de acercarnos a la geografía y sociología electoral de los pueblos y comarcas alicantinos, presentando datos que hasta ahora dormían en su mayor parte en los archivos. Cuestiones claves, como el comportamiento de los anarquistas ante estas elecciones, se entienden mucho mejor -como se verá- desde el análisis de los resultados en núcleos urbanos y rurales de influencia anarquista - caso de Alcoy y Elda en la provincia- y, por tanto, de mayor tradición abstencionista.

Si bien la base y la magnitud de este trabajo se encuentra en el manejo de los datos electorales, no hemos descuidado el manejo de otro tipo de fuentes -la mayoría, de la abundante prensa-, para tratar de dibujar con los mayores trazos posibles la compleja coyuntura política nacional y provincial.

Finalmente, durante la II República se celebraron tres elecciones generales a Cortes. Las de febrero de 1936 fueron las últimas y también las más decisivas:

3. Muchos estudios no superan el ámbito local. Por referirnos exclusivamente a los del ámbito provincial alicantino, destacaremos: GARCÍA ANDREU, Mariano, Alicante en las elecciones republicanas 1931-1936, Alicante, Universidad de Alicante, Ayuntamiento de Alicante, 1985. COSTA VIDAL, Francisco, Villena durante la II ${ }^{a}$ República, Alicante, 1989. HERNÁNDEZ FERRIS, Rafael, Les eleccions a Alcoi (1931-1936), pp. 125-145. En LAlcoi del segle XX. V Jornades d'Històrica Local, Alcoi, Arxiu Municipal d'Alcoi, Centre Alcoià d'Estudis Històrics i Arqueològics, 2002. MARTÍNEZ LEAL, Juan, Los socialistas en acción. La Segunda República en Elche (1931-1936), Alicante, Universidad de Alicante, 2005. FORNER MUÑOZ, Salvador, Las elecciones de 1933 en Elda. Ideologías y comportamiento electoral en un núcleo industrial, en Coloquio Internacional II República Española, Barcelona, 1981. 
pocos meses después estallaría la guerra civil. El vínculo entre un hecho y otro resulta pues inevitable y Javier Tusell lo expresó de forma sugestiva y tremendamente plástica: en esas elecciones, dice "se enfrentan con la papeleta del voto, en las urnas, dos Españas que cinco meses después comenzarían a matarse con las armas en la mano en las trincheras" ${ }^{4}$. Pese a su evidente esquematismo, esta apreciación, omnipresente en distintos ámbitos historiográficos, permite ya visualizar la enorme trascendencia de estos comicios, pues -como veremos-en ellos parecía dirimirse algo más que unas mayorías parlamentarias y de gobierno. Al adentrarnos en el estudio de esta coyuntura política resulta impactante que ya antes de conocerse sus resultados, en los planteamientos y en el ardor propagandístico, se considerara estas elecciones como las últimas en paz, tal fue la proliferación de mensajes de exclusión y de violencia anunciando lo que ocurriría a cuenta de los resultados. Si ganaban las derechas la República estaba perdida, si ganaba la izquierda se desencadenaría la Revolución.

\section{La convocatoria electoral: coyuntura política y formación de las candidaturas}

Durante los últimos meses de 1935 se fue escenificando el fracaso de los gobiernos de centro-derecha que habían de "rectificar" la República, o al menos estabilizar políticamente el Régimen, tras lo que modernamente se llamaría la "alternancia". Las razones de este fracaso son complejas, pero ni la experiencia primero de centro-izquierda ni la de centro-derecha después lograron agotar dos años de legislatura tras ensayar distintas fórmulas de gobierno ${ }^{5}$. Ninguna de las dos opciones llegaría en realidad a reconocer la legitimidad de los adversarios políticos ni establecer un mínimo consenso sobre las reglas básicas del sistema político, como tendremos ocasión de mostrar en las proclamas, propaganda y prácticas políticas del periodo electoral ${ }^{6}$.

4. TUSELL, Las elecciones..., p. 12.

5. La II República tuvo el dudoso honor de ser el régimen parlamentario europeo con mayor inestabilidad gubernamental. Durante el Bienio de Derechas hubo 10 cambios de gobierno. Los gobiernos constituidos entre octubre de 1934 y febrero de 1936 tuvieron una duración media de 72 días. Vid. MONTERO, José Ramón,"Las derechas en el sistema de partidos del segundo bienio republicano: algunos datos introductorios". En La II República española. El bienio rectificador y Frente Popular 1934-1936, IV Coloquio de Segovia sobre Historia Contemporánea, Madrid, Siglo XXI, 1988.

6. En lo que se refiere a las dificultades de estabilización democrática y las políticas de exclusión, vid. DEL REY, Fernando (dir.), Palabras como puños. La instransigencia política en la II República, Madrid, Tecnos, 2011. Para dos visiones diferentes del final del periodo republicano en paz, vid. PAYNE, Stanley G., El colapso de la República. Los orígenes de la guerra civil (1933-1936), Madrid, 2005. Otra visión, CRUZ, Rafael, En el nombre del pueblo. República, rebelión y guerra en la España de 1936, Madrid, Siglo XXI, 2006. 
En lo que se refiere a la coyuntura inmediata, durante la segunda mitad de 1935 se asiste al derrumbe del Partido Republicano Radical de Lerroux, especialmente tras los escándalos de Nombela y estraperlo. Meses éstos en los que tuvieron gran trascendencia política las decisiones del presidente de la República. En la crisis de septiembre, Alcalá Zamora, tras fracasar con otros candidatos, concede la jefatura del gobierno a Joaquín Chapaprieta, torrevejense, experto abogado en derecho financiero y administrativo, que en los meses anteriores había mostrado su competencia tratando de equilibrar el presupuesto y la deuda pública en el Ministerio de Hacienda. Republicano independiente y sin fuerza parlamentaria propia, logró formar gobierno con el apoyo a regañadientes de Lerroux y Gil Robles. Pero apenas pudo llegar al mes de diciembre: cuando presentó algunas tímidas medidas de reforma de los impuestos, la CEDA le retira su apoyo parlamentario. La crisis decisiva sobrevino cuando el presidente de la República, en la dramática entrevista del 11 de diciembre, se niega a dar la jefatura del gobierno a Gil Robles, tal como éste exigía de una manera apremiante $e^{7}$ : "Antes la disolución de las Cortes", le dijo Alcalá Zamora. "Triunfen en las urnas las derechas o las izquierdas, no quedará otra salida, por desgracia, que la guerra civil", le contestó Gil Robles.

Metido en el laberinto de sus propias decisiones, que tantas animadversiones le habrían de provocar entre la clase política, Alcalá Zamora nombró jefe del Gobierno a Portela Valladares, con el propósito ya prácticamente explícito de llevar al país a unas nuevas elecciones generales en pocos meses. Portela, que ni siquiera era diputado, carecía de fuerza política, pero en su encargo estaba implícito formar una opción política de centro avalada por Alcalá Zamora para tratar de evitar la desestabilización de la República. Pero los hechos se precipitaron tras la airada reacción de las derechas a la decisión de prorrogar el presupuesto y suspender un mes más las sesiones de Cortes. El día 7 enero de 1936 se publicaban sendos decretos, firmados por el Presidente de la República, uno disolviendo las Cortes y otro convocando elecciones generales a Cortes. La campaña daría comienzo el 12 de enero, el 9 de febrero se procla-

7. Recientemente, se han publicado los diarios del Presidente de la República, Alcalá Zamora, imprescindibles para comprender tanto los trascendentales hechos que estaban ocurriendo, como de la perspectiva que sobre los mismos nos lanza quien se sabía ya cuestionado por casi todos y condenado a su destitución. El libro ha sido titulado Asalto a la República, la edición está a cargo de Fernández Capel, Madrid 2011, que si bien ha hecho un esfuerzo por clarificar el contexto, es excesivamente descalificador respecto a los oponentes políticos de Alcalá Zamora. La entrevista citada y su relación con Gil Robles está extensamente tratada en sus Memorias (edición consultada: Barcelona, Esfera de los Libros, 1998). Vid. especialmente la p. 390 y ss. Para la versión de Gil Robles, vid. sus memorias No fue posible la paz, Madrid, Ariel, 1968 (edición consultada de 2006; vid. especialmente p. 314 y ss.) 
marían los candidatos por la Junta Provincial Electoral. Los comicios se celebrarían el 16 de febrero en primera vuelta y el 1 de marzo en segunda vuelta en aquellas circunscripciones en donde los candidatos no hubieran superado el mínimo del $40 \%$ de los sufragios emitidos, tal y como exigía la ley.

Para que la campaña y las elecciones se desarrollaran en un ambiente de normalidad democrática aceptable, Portela levantó el estado de alarma y con ello la censura de prensa, realizó importantes nombramientos tanto en la administración central como de los gobernadores civiles, reponiendo en algunos lugares los ayuntamientos democráticos del 14 de abril. Para evitar incidentes, el Gobierno prohibió los mítines y las manifestaciones al aire libre durante toda la campaña electoral.

El 31 de diciembre fue nombrado gobernador civil de Alicante, Alejandro Vives Roger, ex radical. El 7 de enero fue constituida una nueva gestora de los ayuntamientos de Alcoy, Orihuela y Alicante, afín a las tesis portelistas. Dando un paso más, el día 29 de enero, en plena campaña, tras intensas gestiones del Subsecretario de la Presidencia Miguel Cámara Cendoya, fueron restituidos los ayuntamientos democráticos de Alicante, Orihuela y Alcoy. Los tres ayuntamientos serían destituidos nuevamente a los pocos días, en puertas de la jornada electoral, "por excitar las pasiones públicas incitando el desorden con fines políticos en abierta rebeldía contra el Gobierno de la Nación"8. Todo ello en un contexto de manejos electorales que explicaremos más adelante.

\section{La candidatura del Frente Popular}

La idea del Frente Popular se fue gestando durante el año 1935 como resultado del cruce de al menos tres vectores. El primero de ellos lo fue expresando el dirigente socialista Indalecio Prieto en su periódico El Liberal, desde marzo de ese año, en una serie de artículos de gran difusión bajo el título de Posiciones socialistas. En ellos, desengañado también de la experiencia revolucionaria de octubre de 1934, se mostraba partidario de un nuevo entendimiento del PSOE con los republicanos, para no repetir el desastre electoral de 1933. El segundo vector fueron las propias reflexiones de Azaña, que en los primeros meses consiguió avances en la unidad de acción de las fuerzas republicanas de izquierda. En su correspondencia con Prieto, Azaña le contestó acerca de las alianzas: "No necesita usted recomendarme la necesidad de una coalición. Habla usted a un convencido". Enaltecida su figura tras la persecución de Octubre, Azaña era el personaje indiscutible para liderar una nueva coalición de izquierdas, y

8. El texto completo RAMOS, Vicente, Lorenzo Carbonell, alcalde popular de Alicante, Alicante, Ed. del autor, 1986, pp. 199-200. 
así lo expuso y se demostró en sus grandes mítines de 1935, especialmente en el mitin de octubre de Comillas?.

El tercer vector, de mucho menor calado en el proceso español, proviene del mundo comunista, tiene su impulso en Francia y encuentra su formulación acabada en el VII Congreso de la Internacional Comunista, celebrado en julio de 1935 en Moscú, al definir la política de Frentes Populares basada en la unión de las fuerzas obreras en un frente único extensible hacia las fuerzas de la burguesía democrática, con el fin de cerrar el paso al fascismo. Los comunistas eran entonces muy minoritarios en España, pero estos planteamientos conectaban en gran medida con el sentimiento de las clases populares, especialmente tras la derrota y represión de la Revolución de Octubre y la existencia en las cárceles de miles de militantes de la izquierda. En estas circunstancias, Largo Caballero, radicalmente enfrentado a Prieto no tuvo más remedio que aceptar el pacto del Frente Popular, exigiendo la inclusión de los comunistas que no estaba prevista en los planes iniciales del tándem Azaña-Prieto ${ }^{10}$.

En la segunda mitad de diciembre de 1935 comienzan los contactos entre los representantes del PSOE y los partidos republicanos. El 23 se forma el Comité Electoral encargado de redactar el programa, que se dio a conocer el 15 de enero ya en campaña electoral ${ }^{11}$. El 9 de enero comenzaron los contactos y el 17 de enero se constituía el Frente Popular en la provincia de Alicante, en una reunión en la que participaron el PSOE, IR, UR, PCE, UGT y el Partido Sindicalista. En días posteriores se irían creando los comités del Frente Popular en otros pueblos de la provincia ${ }^{12}$.

La designación de candidatos no estuvo exenta de tensiones, especialmente en las candidaturas republicanas. Franklin Albricias, Antonio Pérez Torreblanca y Gregorio Ridaura, destacados dirigentes acabaron renunciando por desavenencias internas o por falta de entendimiento con los socialistas. Eso propició

9. Para el proceso de formación del Frente Popular, sigue siendo la referencia esencial el libro de JULIÁ, Santos, Los orígenes del Frente Popular, Madrid, Siglo XXI, 1972, pp. 191192. La carta de Azaña es del 10 de abril de 1935.

10. Recuérdese la desdeñosa referencia que hizo en sus memorias Largo Caballero hacia Prieto, al que le atribuía nada menos ser "el mozo de estoques de don Manuel Azaña". La cita en Mis recuerdos. Cartas a un amigo, México, Ediciones Reunidas, S. A., 1976, p. 141.

11. Se ha hablado mucho del alcance del programa electoral del Frente Popular. Citaremos tan sólo, para confirmar su carácter reformista, los célebres rechazos de los republicanos a las pretensiones más radicales del PSOE, explícitos en el propio manifiesto electoral, en concreto el rechazo al principio de nacionalización de la tierra y su entrega a los campesinos, la medidas de nacionalización de la Banca, como tampoco aceptaron la propuesta del control obrero sobre las empresas.

12. Vid. El Luchador, 17-I-1936 y ss. El prestigioso diario de los republicanos de izquierdas es imprescindible para el seguimiento de la campaña del Frente Popular. 
la entrada a última hora en liza de Eliseo Gómez Serrano ${ }^{13}$. Entre los socialistas también hubo disputas por el orden de prelación, al elegir seis candidatos la Agrupación Provincial sobre los cuatro candidatos que había fijado Madrid. La Asamblea de Izquierda Republicana rechazó la candidatura de Manolita Luque, presidenta de Unión Republicana Femenina, no sin sonoras protestas de sus correligionarias ${ }^{14}$.

Queda una última cuestión a dilucidar, insinuada por la prensa de derechas alicantina, y abiertamente expuesta por Joaquín Chapaprieta en sus memorias. Se trata de las maniobras del gobierno de Portela Valladares para llegar a un acuerdo con el Frente Popular en Alicante y hasta qué punto esa fue la contrapartida para reponer los ayuntamientos populares. La amenaza de acuerdo con las izquierdas sería un elemento de presión hacia las derechas alicantinas, para forzar su inclusión gubernamental ventajosa en la candidatura derechista, como efectivamente ocurrió ${ }^{15}$.

El encaje definitivo de los candidatos se realizó en Madrid el 21 de enero, quedando finalmente la candidatura del Frente Popular en Alicante compuesta por cuatro miembros del PSOE (Rodolfo Llopis, Miguel Villalta, Salvador García y Ginés Ganga), tres de Izquierda Republicana (Carlos Esplá, Juan J. Cremades y Eliseo Gómez Serrano), y uno de Unión Republicana (Jerónimo Gomáriz) ${ }^{16}$.

\section{La candidatura de derechas en Alicante}

La candidatura de derechas tuvo muchos más problemas para perfilarse, porque las desavenencias en la tarea de gobierno eran demasiado recientes. Por otro lado, era una tarea casi imposible unir a un arco ideológico tan diverso, desde los partidos claramente fascistas como Falange, hasta los republicanos conservadores y de centro, pasando por monárquicos, agrarios, etc. Pero la propia legislación electoral, que primaba la formación de coaliciones y la evidencia de la unión de toda la izquierda en el Frente Popular, un temible competidor electoral, empujaba a las derechas a formar al menos un amplio frente. Ante la caída en picado de las expectativas del Partido Radical, Gil Robles se con-

13. En un artículo de necrológica ante la noticia del fusilamiento de Eliseo Gómez Serrano, Carlos Esplá refirió en términos emotivos la inclusión de Gómez Serrano en la candidatura. GÓMEZ SERRANO, Eliseo, Diarios de la guerra civil (1936-1939), Alicante, Universidad de Alicante, 2008. Vid. anexo, pp. 711-713.

14. Diario de Alicante, 26-I-1936. Este periódico hizo campaña sobre todo a favor de Chapaprieta y la coalición de derechas.

15. CHAPAPRIETA, Joaquín, La paz fue posible. Memorias de un político, Barcelona, Ariel, 1972.

16. Para los interesados en la biografía de estos candidatos y posteriormente diputados, vid. PANIAGUA, Javier y PIQUERAS, José. A., Diccionario biográfico de políticos valencianos, 1810-2003, Valencia, Institució Alfons el Magnànim, Diputació de València, 2003. 
virtió en el árbitro de cualquier alianza, aunque con la inesperada intromisión de Portela Valladares y su Partido de Centro que desde el gobierno presidiría los comicios controlando el aparato administrativo, electoral y el orden público. En este difícil juego de equilibrios, Gil Robles decidió llegar a pactos con las distintas fuerzas de centro y de derechas, según las circunstancias políticas de cada demarcación electoral, sin llegarse a un manifiesto conjunto ni a una coordinación a escala nacional. Esta posición llevó a una mayor dispersión, a generar inevitables tensiones con fuerzas minoritarias y a exacerbar personalismos; de ahí que el cierre de candidaturas se hiciera también muy avanzada la campaña electoral ${ }^{17}$. Una buena muestra lo fue el País Valencià, en el que el perfil de las candidaturas variaba según la provincia. En Valencia, la Derecha Regional Valenciana (DRV) de Luis Lucia (adscrito a la CEDA, como se sabe) compartía candidatura con los monárquicos de Renovación Española y con la Comunión Tradicionalista. En Castellón, DRV irá al copo por las mayorías, sin haber llegado a un acuerdo con los tradicionalistas ${ }^{18}$.

El caso de Alicante -como así se le conoció- será diferente. En la provincia, la Derecha Regional Agraria (DRA) (nombre de DRV en Alicante) tenía menos fuerza y además tenía que competir con los republicanos independientes de Chapaprieta (que acababa de dejar la Presidencia del Gobierno) y con las pretensiones del gobierno de Portela. Las memorias de Chapaprieta constituyen un excelente testimonio de los avatares del proceso y de los entresijos de las negociaciones ${ }^{19}$.

Resumiendo mucho, la idea inicial de Rafael Alberola, el presidente provincial de DRA, era tener cinco candidatos de los ocho a elegir por las mayorías en la provincia. Había mantenido contactos con Vives, el gobernador civil, un radical reconvertido al portelismo, quien había pedido inicialmente dos puestos para el Gobierno. En principio DRA solo aceptaba uno del Gobierno, uno monárquico y otro para un republicano independiente que era Chapaprieta. Se sucedieron reuniones con Gil Robles en Madrid y con Luis Lucia en Valencia. Los tradicionalistas (que en Alicante tenían en Senante una personalidad destacada aunque en declive), los radicales y los monárquicos también aspiraban al menos a un puesto en la candidatura. Es entonces, cuando Portela lanzó un auténtico órdago en la provincia de Alicante, al reclamar nada menos que cua-

17. Las memorias citadas de GIL ROBLES, No fue posible la paz..., p.380 y ss. y las referencias de TUSELL, Las elecciones..., especialmente p. 42 y ss, son inexcusables para comprender el proceso a escala nacional de formación de las alianzas electorales de la derecha.

18. AGUILÓ, Luis, Las elecciones en Valencia durante la II República, Valencia, Facultad de Derecho, Universidad de Valencia, 1976.

19. CHAPAPRIETA, La paz fue posible... Vid. especialmente el cap. IX, pp. 385-401. 
tro candidaturas, amenazando con llegar a un acuerdo con el Frente Popular alicantino, al que habría ofrecido garantías de alcanzar las izquierdas los ocho puestos de la mayoría a cambio de que por las minorías salieran tres diputados del Gobierno. Para Chapaprieta, una muestra de que este acuerdo era real fue la reposición de ayuntamientos populares, que crearon un ambiente de temor en las derechas. Un muñidor clave de todos estos manejos fue Miguel de la Cámara Cendoya, que había sido diputado radical por Alicante las dos legislaturas anteriores y ahora era Subsecretario de la Presidencia con Portela. Esto explicaría que Gil Robles aceptara tres candidatos del Gobierno por Alicante, quedando finalmente la candidatura formada por tres miembros de Derecha Regional Valenciana, tres del Gobierno, uno del Partido Republicano Independiente y un Independiente, Silvino Navarro, que en realidad era un tapado de DRA.

Este giro, que fue calificado por la prensa local de "sensacional"20, causó bastante malestar, en especial la eliminación del jefe de DRA en Alcoy, Enrique de Juan. DRA optó por Rafael Alberola, jefe provincial del partido y por dos candidatos de las comarcas de la Marina Alta y la Vega Baja, donde más fuerza tenía la derecha. En el caso de los candidatos del gobierno, entraron José Canalejas, que se había pasado del lerrouxismo y los monárquicos a las filas de Portela; el segundo nombre era el ya citado Miguel de la Cámara Cendoya. Causó sorpresa y malestar la designación de un tercero, Baldomero Martínez de León, un absoluto desconocido sin residencia en Alicante, lo que se advertirá en los resultados. Todo ello propició candidaturas independientes de derechas, siendo las de mayor relieve la de Manuel Senante, tradicionalista histórico, director de El Siglo Futuro. César Oarrichena, un histórico republicano radical también presentaría candidatura independiente. En conjunto restarían un puñado de miles de votos, pero sin incidencia en el resultado final.

\section{La campaña electoral}

Cara a la confrontación del 16 de febrero, ambos bloques de derechas y de izquierdas eran plenamente conscientes de que la contienda electoral tenía visos de encrucijada. Más allá de la letra de los programas, en las actitudes, en los lemas, en los inflamados discursos y artículos periodísticos, en las pasiones políticas desatadas en suma, se advierte más que un enfrentamiento electoral, un choque entre bloques sociológicos, políticos y culturales excluyentes. Para muchos testigos y protagonistas, que nos fueron dejando después su testimonio, esta contienda electoral fue una auténtica encrucijada vital, en la que se jugaba el destino individual y colectivo.

20. El Correo, 8-II-1936. De orientación católico-tradicionalista apoyó a Manuel Senante, pero contiene interesante información sobre el discurrir de la campaña en la provincia. 
Desde enero de 1936 las páginas de la prensa alicantina están repletas de llamadas apocalípticas al voto como si en ello fuera la propia vida, pero pocos tan gráficos como el que apareció en el diario alicantino derechista Más: "A las urnas alicantinos: ¡A morir o vencer! Conquistemos el derecho a la vida en las papeletas electorales"21.

Resulta muy significativo que por ambas partes se utilizaran en los mítines el término "Cruzada" para sacralizar el combate contra el adversario. Así lo hizo el comunista Vicente Alcalde en el Monumental para referirse a la lucha contra las derechas ${ }^{22}$ y así se hizo, por ejemplo, en la gran concentración de las Juventudes de Acción Popular (JAP) en Castalla ${ }^{23}$.

Descripciones horripilantes se realizaban en los recuadros de prensa advirtiendo de lo que sucedería si triunfaba el adversario político. Por ejemplo, en El Obrero de Elche si ganaba la CEDA: "Es traer a España el hambre, la Inquisición, la violación, la muerte" ${ }^{24}$. Por su parte, El Eco, el periódico ilicitano de la derecha advertía que de triunfar las izquierdas España se convertiría en una "República de atracadores de todas clases, organizada en barbarie permanente al servicio de Moscú" 25 . El diario provincial de la derecha, Más repetía esos días el siguiente recuadro: "Lo que os espera si gana el marxismo: Disolución del ejército. Aniquilamiento de la Guardia Civil. Armamento del pueblo. Incendio de Bancos y casas particulares. Reparto de bienes y tierras. Reparto de mujeres. ¡¡Ruina, ruina, ruina!!”. Ese mismo día, el gran titular a toda plana decía: "Estas Cortes serán las segundas y definitivas"26.

Incluso Diario de Alicante, republicano conservador, publicaba el siguiente perfil electoral: "Están ya trazados los contornos de la lucha. Los de octubre y los otros. Los fariseos, cómplices y colaboradores de la revolución y los otros. Los que quieren hacer a España tributaria de Rusia y colonia soviética, y los que queremos paz, orden, trabajo y progreso". Luego llama a votar con entusiasmo "No en defensa de una candidatura, sino en la defensa de la civilización contra la barbarie, de la decencia y la moralidad política frente al salvajismo". "Abstenerse es un delito contra España" ${ }^{27}$. En definitiva, "Por España y contra la revolución y sus cómplices" sería el lema general de la campaña de las derechas.

21. Más, 15-II-1936. Diario de la Derecha Regional en Alicante, es la fuente principal para la campaña de la coalición de las Derechas.

22. El Luchador, 11-II-1936.

23. Más, 4-II-1936.

24. El Obrero, 9-II-1936. Semanario de los socialistas ilicitanos.

25. El Eco, 9-II-1936. Semanario de las derechas ilicitanas.

26. Más, 11-II-1936.

27. Diario de Alicante, 15-II-1936. 
Más notable y moderado fue el editorial de El Luchador, el diario del republicanismo de izquierdas, la víspera de las votaciones. Seguro del triunfo popular en Alicante, el diario llamaba al voto masivo y a la contención frente a las provocaciones. Terminaba con los lemas: “¡Por la amnistía! ¡Por Alicante! ¡Por la República!"28. Estos planteamientos contrastaban con la primera plana del diario Más, que con grandes caracteres tipográficos clamaba:" ¡Españoles! ¡En pie! La Patria en peligro os necesita para defenderse y aplastar definitivamente a la revolución que quiere destrozarla. Mañana es la lucha decisiva; revolución o contrarrevolución; civilización o barbarie; ser o no ser"29.

La campaña, como reflejaban los periódicos alicantinos, fue intensa, apasionada y febril. En este clima de pasiones desatadas todo hacía presagiar incidentes violentos, lo que llevó al Gobierno a activar al máximo la vigilancia en las calles y a prohibir los actos en lugares abiertos, impidiendo además la exhibición de uniformes o prendas paramilitares. Sólo la CNT provincial lanzó un manifiesto el 7 de febrero llamando a la abstención electoral, que contenía violentos párrafos contra el Frente Popular, recordando viejas heridas como Casas Viejas. ${ }^{30}$. Pero la encrucijada que estos comicios supusieron para la tradicional posición abstencionista del mundo ácrata, queda perfectamente ilustrada con la llamada activa al voto que hizo El Boletín, publicación anarquista alcoyana ${ }^{31}$. También la minúscula Falange alicantina preconizaba inicialmente la abstención, para después pedir el voto a su jefe nacional, pese a no presentarse candidato.

Al prohibirse los actos en recintos abiertos, proliferaron por toda la provincia los mítines en cines, teatros y sedes, pero especialmente el cartelismo, pasquines, octavillas y propaganda de prensa, junto con la radio que cada vez tenía más importancia. Mucha menos referencia encontramos en la prensa de la oratoria electoral desplegada en los mítines, en cualquier caso redundante con los ejemplos ya expuestos. La única figura de alcance nacional que visitó estas tierras fue el socialista Largo Caballero. El mitin fue precedido de una gran expectación con grandes recibimientos al líder ugetista en Villena, Elda y Elche el día anterior. El gobernador denegó la plaza de toros y se realizó en el Cine Monumental el día 26 de enero a las 10’30 de la mañana. Miles de personas venidas de toda la provincia abarrotaron el recinto y otras tantas quedaron

28. El Luchador, 15-II-1936.

29. Más, 15-II-1936.

30. El Correo, 8-II-1936.

31. Decía El Boletín, 1-II-1936: "Es la hora de actuar y sentar un precedente para el porvenir de la clase obrera y adoptar posiciones equívocas como las que se adoptaron en el 33, para ayudar a la entronización del fascismo, más que contraproducente, sería catastrófico". 
fuera escuchando por megafonía las palabras del líder socialista. El mitin se transmitió también por radio a otros dos cines y a la sede socialista. Curiosamente, mientras que la prensa alicantina, incluso de la derecha, no destacó nada especialmente, afirmando que había estado menos revolucionario que otras veces, la prensa de Madrid destacó la frase: " (...) si ganan las derechas tendremos que ir a la guerra civil declarada", que tuvo un gran eco nacional ${ }^{32}$.

Sólo en este clima de enorme ansiedad social puede entenderse la inmensa polémica que se desató a cuento de unas supuestas palabras del alcalde de Alicante, Lorenzo Carbonell en la reposición del Ayuntamiento democrático. Cuando tomó posesión, el día 19 de enero, en un clima de gran fervor popular, el alcalde Carbonell tuvo que salir varias veces a saludar al balcón del Ayuntamiento, desde el que pronunció algunas palabras que nadie de la prensa local recogió. Sin embargo, algunos diarios nacionales -al parecer con origen en el Ya y El Debate- publicaron unas supuestas palabras en las que el alcalde instaba a no dejar votar a las mujeres beatas y cortar cabezas de las derechas después del triunfo popular ${ }^{33}$. Pese a que el alcalde telegrafió a las altas instancias de la nación denunciando la infame campaña contra él, acompañándolo de ejemplares de la prensa local, los comentarios siguieron arreciando. Portela Valladares, interpelado por los periodistas dijo que había encargado un informe completo al Gobierno Civil de Alicante. En efecto, a resultas de los informes fueron nuevamente destituidos los Ayuntamientos de Alicante, Alcoy y Orihuela. Que se trató de una burda manipulación, lo deja patente las palabras recogidas por el secretario en el acta municipal al finalizar la sesión, en donde se puede leer la decisión de Carbonell de dirigirse a la multitud para que "no haya un grito ni nada que puedan aprovechar nuestros enemigos en desprestigio del pueblo de Alicante". Una vez en el balcón, tras anunciar su confianza en el triunfo electoral dijo: "Alicantinos: el 16 de febrero, las urnas hasta el tope. Ni uno a las derechas, que son los enemigos de España". Una oratoria excluyente, desgraciadamente corriente en los discursos, pero sin ningún atisbo de llamada a la coacción y la violencia.

En medio de todo este crispado clima menudearon los incidentes violentos, en forma de choques callejeros, entre propagandistas de distinto signo en Alicante pero sin llegar a extremos irreparables. Algunos de los más destacados ocurrieron en la capital ${ }^{34}$. El día 23 de enero un grupo de jóvenes derechistas

32. El discurso en El Luchador, 27-II-1936.

33. El seguimiento más detallado de estos hechos lo realizó Vicente Ramos, Lorenzo Carbonell..., pp. 195-201. La cita literal está tomada del Libro de Actas de Sesiones de Pleno del Ayuntamiento de Alicante, AMA.

34. Para todos estos incidentes en la capital, vid. El Luchador de los días que se citan en el texto. 
hizo estallar petardos en la Escuela de Comercio, hiriendo levemente a un estudiante. El día 3 de febrero se produjo un altercado tumultuario en el Mercado Central de Alicante, al insultar gravemente la dueña de un puesto, a uno de los niños asturianos acogidos en Alicante. Un grupo de personas la agredieron y asaltaron su puesto, destrozándolo. Uno de los más graves fue el asalto pistola en mano, el día 5 de febrero, a la redacción de El Luchador, el más influyente diario de la izquierda alicantina, por parte de un grupo de jóvenes falangistas. Afortunadamente el incendio pudo ser sofocado por los propios obreros. El 10 de febrero, frente al Diario de Alicante, se produjo un enfrentamiento entre falangistas y militantes de Izquierda Republicana, en el que se llegaron a esgrimir pistolas, pero en el que sólo se registraron heridos leves atendidos en la Casa de Socorro. El 12 de febrero un grupo que pegaba carteles de las derechas se enfrentó a la Guardia de Asalto en el barrio de Carolinas, con disparos al aire y lesiones también leves.

En los pueblos de la provincia los incidentes más serios de los que tenemos noticia se produjeron en Callosa de Ensarriá, el 9 de febrero, durante una manifestación en la que se apedreó la casa de un dirigente derechista ${ }^{35}$. Se debió dar un importante ejercicio de autocontención en algunos pueblos, como Elche, cuando se supo que el delegado gubernativo para las elecciones sería nada menos que Juan Sansano Ibarra, el líder de Derecha Ilicitana. Este designó a 40 agentes de vigilancia del proceso electoral entre elementos derechistas. Ambas partes se acusaban de coacciones y amenazas a los electores. En Elche, el incidente más serio se produjo en la noche del 13 de febrero frente a la sede de Derecha Ilicitana, al enfrentarse un grupo muy numeroso de propagandistas de ambos bandos. Resultó herido un guardia municipal y varios de los participantes en la reyerta ${ }^{36}$. El 11 de enero se produjo un incendio intencionado en la ermita de San Antón de Elche y al día siguiente otro en la partida de Verdegás en Alicante. Así se llegaba a la jornada electoral.

\section{Los resultados electorales}

\section{Del sistema electoral y las fuentes utilizadas}

El sistema electoral republicano establecía como distrito electoral básico la provincia, aunque hacía excepciones (Decreto 8/05/1931, modificado por la Ley 28/07/ 1933). El sistema era de tipo mayoritario corregido a dos vueltas y con listas abiertas, adjudicándose un número de escaños a las mayorías y otro a las

35. Sumario A-690 Audiencia Territorial de Callosa Ensarrià. Archivo Histórico Provincial Alicante (AHPA).

36. Sumario 19, A-273, Audiencia Territorial de Elche, AHPA. 
minorías en cada circunscripción (la proporción era de 70\% a 80\% para las mayorías). En el caso de la provincia de Alicante, sobre once escaños en disputa, ocho se adjudicaban a las mayorías y tres a las minorías, de modo que la candidatura que obtuviera el mayor número de votos podía obtener los ocho escaños, si se daba la suficiente disciplina por parte del elector. El votante podía en su papeleta emitir hasta ocho votos, es decir, el máximo que correspondía a la mayoría y también podía votar menos o completar sus opciones votando a otras candidaturas. En el caso de que ninguno de los candidatos hubiera obtenido el $40 \%$ de los votos en la primera vuelta, debía celebrarse una segunda vuelta en el plazo de 15 días. El sistema, en principio, estaba pensado para concentrar las opciones políticas y formar grandes coaliciones.

La experiencia desastrosa de las elecciones de 1933, en donde los socialistas y los republicanos habían acudido muy desunidos, fue decisiva para la formación del Frente Popular. El hecho de que se concurriera a estas elecciones en grandes coaliciones tanto en el espacio de la derecha como de la izquierda, hace muy difícil -por no decir imposible- sacar conclusiones sobre la decantación partidista del electorado.

Para presentar los resultados locales, comarcales y provinciales hemos utilizado fuentes variadas. Se tenía como punto de partida las investigaciones electorales para Alicante, Elche, y Villena ${ }^{37}$. Todos estos trabajos tenían como fuente las actas de las mesas electorales cuya documentación se conserva en Salamanca, en el entonces llamado Archivo Histórico de la Guerra Civil Española. Para estas localidades hemos partido de estas fuentes. Para el resto se ha tenido como fuente los resultados electorales publicados en el Boletín Oficial de la Provincia de Alicante, como era preceptivo por la ley electoral (art. 45). Los datos fueron apareciendo por mesas electorales y distritos de cada localidad con expresión de los votos por candidato, por lo que había que sumar los de cada uno de los candidatos hasta obtener el total de votos por candidatura y por localidad que es como se presentan los resultados en este trabajo. Para ello se tuvo que reubicar los municipios, que estaban organizados por partidos judiciales, en las comarcas actuales.

En julio de 1936, al comenzar la guerra, dejaron de publicarse, lo que afectó a los datos de la Vega Baja, el Bajo y el Alto Vinalopó. Para estos datos se tuvo que acudir a las Actas del Archivo de Salamanca. El Boletín tiene además el inconveniente que no publicaba los datos de votantes y electores, sino exclusivamente los votos obtenidos por los distintos candidatos.

37. Vid. la reseña de estos estudios en la nota a pie página número 3, supra. 
Procurando completar geográficamente los resultados, nos encontramos con la mayor sorpresa archivística de la investigación, al aparecer perfectamente catalogado en el Archivo de la Diputación Provincial (AHDPA), el Acta del Escrutinio Oficial realizada por la Junta Provincial Electoral ${ }^{38}$ que en anteriores intentos, años atrás, no había aparecido. El resultado provincial global del escrutinio oficial había sido publicado en la prensa provincial en su día ${ }^{39}$, pero en el Acta del Escrutinio Oficial constan los votos obtenidos por cada candidato, mesa a mesa, localidad a localidad hasta el total provincial. También se hacían constar las incidencias de las que en su momento hablaremos. El Acta contiene el número de votantes en cada mesa, pero no incluye el de electores y concluye con la proclamación oficial de diputados electos. Así pues, esta fuente se constituyó en la referencia base de cualquier cálculo y duda.

Sin embargo para completar el cuadro electoral faltaba el dato de la participación y la abstención, al no aparecer por ningún lado el censo electoral. Se tuvo pues que recurrir a los originales de las actas de las mesas electorales que se conservan en el actualmente llamado Centro Documental de la Memoria Histórica de Salamanca (CDMHS). El serio inconveniente que nos encontramos fue la irregularidad de las actas, con grandes lagunas en muchísimas localidades de la provincia, lo cual hacía imposible el cálculo de los datos de participación. Para subsanar este inconveniente se ha tenido que acudir a las actas de la elección de compromisarios para elegir Presidente de la República que se celebró dos meses después, el 26 de abril, que se conservan prácticamente completas en dicho Archivo. La comparación de datos entre los comicios de febrero y abril (cuando ello era posible) mostraban una concordancia prácticamente absoluta, lo cual nos decidió a utilizar el dato de electores en las elecciones de compromisarios, un método indirecto pero absolutamente fiable para el cálculo de la participación en las elecciones de febrero de 1936. Sólo en 18 mesas de 1.349 en toda la provincia en las que no había dato hemos debido acudir a la estimación para no distorsionar los resultados finales de participación. Aun con ello, la mayor discrepancia de nuestros cálculos -como veremos a continuación- y el oficial se sitúan en este punto de la participación.

Por último, hemos optado por presentar los datos de resultados en términos de votos totales a la candidatura y votos medios, es decir, la resultante de dividir los totales por los ocho diputados de la mayoría en disputa. No es posible realizar sin desvirtuar la misma operación para los votos a otras candidaturas unipersonales como se reflejará en el cuadro (otros). También se ha elegido agru-

38. A partir de ahora AEOJPE, Archivo Histórico de la Diputación Provincial de Alicante (AHDPA), GE-14747-1.

39. Vid. prensa alicantina citada, 20-II-1936. 
par por las comarcas actuales los datos de los distritos electorales que se correspondían a los partidos judiciales del año 1936.

Llegados a este punto, debo citar y agradecer la eficaz y desinteresada colaboración de Manuel Bañón García, que diseñó y supervisó hasta el final la hoja de cálculo con la que se ha llevado a cabo la agrupación y manipulación de una ingente cantidad de datos.

\section{La participación electoral}

La participación electoral queda expresada en el siguiente cuadro:

Cuadro 1: Participación en las elecciones del Frente Popular en Alicante

\begin{tabular}{|l|c|c|c|c|}
\hline Comarcas & Electores & Votantes & Participación \% & Abstención \% \\
\hline Vega Baja & 57.549 & 43.454 & 75,5 & 24,5 \\
\hline Bajo Vinalopó & 30.933 & 24.317 & 78,6 & 21,4 \\
\hline Medio Vinalopó & 39.074 & 30.612 & 78,3 & 21,7 \\
\hline Alto Vinalopó & 18.374 & 13.657 & 74,3 & 25,7 \\
\hline Alacantí & 61.841 & 46.545 & 75,3 & 24,7 \\
\hline LAlcoià & 34.379 & 27.753 & 80,7 & 19,3 \\
\hline El Comtat & 16.150 & 12.496 & 77,4 & 22,6 \\
\hline Marina Baixa & 22.918 & 15.653 & 68,3 & 31,7 \\
\hline Marina Alta & 47.720 & 30.876 & 64,7 & 35,3 \\
\hline Total & 328.938 & 245.363 & 74,6 & 25,4 \\
\hline
\end{tabular}

Fuente: Elaboración a partir del Acta del Escrutinio Oficial de la Junta Provincial Electoral. AHDPA para los votantes. Para los electores: Actas mesas elecciones 16-II-1936 y actas mesas elecciones compromisarios para la designación de presidente de República, 23-IV-1936. CDMH Salamanca.

De los datos del cuadro se desprende la alta participación, la mayor de todas las consultas electorales realizadas durante el periodo republicano, como ocurrió en el resto de España. Nuestros cómputos superan en 1'5 puntos porcentuales el dato oficial, el 73 '1\% de participación, por razones ya explicadas en el apartado anterior. La cifra se sitúa ligeramente por encima de la media nacional que fue -según los cálculos más aceptados- de un $72 \%$.

En la capital alicantina se registró una participación de $76{ }^{\prime} 5 \%$ frente al $6827 \%$ de la primera vuelta de los comicios de 1933. En algunos casos, especialmente en Alcoy y Elda, el aumento de la participación fue espectacular. Estos núcleos, tradicionalmente de fuerte influencia anarquista, tuvieron un compor- 
tamiento abstencionista en la convocatoria de 1933, 43’7\% de participación en Elda en la segunda vuelta y en torno al 50\% en Alcoy. En estas elecciones, sin embargo, la participación fue de las más elevadas de la provincia llegando al 78'9\% en Elda y al 82'5\% en Alcoy. En La Vila, otro núcleo de neta influencia cenetista, se pasó de un abstencionismo del $67^{\prime} 1 \%$ en la segunda vuelta de 1933 a un $43^{\prime} 1 \%$. Indudablemente, la participación activa de un voto tradicionalmente anarquista fue una de las razones básicas del triunfo aplastante del Frente Popular en estas ciudades. Incluso en Elche, tradicional bastión socialista y con una alta participación en las elecciones de 1933 (75'6 en primera vuelta), en estos comicios, alcanzó el 80'1\%.

La participación fue mayor en los grandes municipios. En los ocho mayores municipios alicantinos, que abarcaban el 43 '32\% de la población provincial, el índice de participación fue de un $767 \%$, y el resto de los municipios, de un $73 ’ 3 \%$. En cuanto a las comarcas, llama la atención la menor participación respecto a la media de las dos Marinas, en especial la Marina Alta con un 647\%. Desgraciadamente, en este y otros casos, se carecen aún de referencias concluyentes para explicar el mayor abstencionismo, salvo quizá en las comarcas citadas la conjunción de pequeños municipios aislados del interior montañoso, tradicionalmente abstencionistas, junto con la existencia de núcleos litorales de proyección marinera. Indefectiblemente, en todos los cómputos de participación los pueblos marineros del litoral muestran los mayores registros de abstencionismo, por lo que habría que apuntar a la ausencia forzada en la mar de los varones adultos. En Santa Pola, la participación fue del 57'6\%, en La Vila del 67'9\%, en Altea el 65’4\%, en Denia el 66'5\%, en Javea el 57'2\% y en Calpe el 31'5\%.

\section{Los resultados electorales: el voto a las candidaturas}

Los datos básicos del recuento en el escrutinio oficial aparecen en el cuadro 2.

La primera observación que conviene realizar es que con los datos ofrecidos por el mismo escrutinio oficial, los porcentajes de votos obtenidos por las candidaturas no se ajustan al cien por cien. Si tenemos en cuenta que los votantes contabilizados en el escrutinio oficial son 244.870 , el porcentaje de votos obtenidos por la candidatura de Frente Popular sería del $53{ }^{2} 2 \%$ y no del $54^{\prime} 0$ y el de la candidatura de Derechas sería del $44^{\prime} 5$ y no del $45^{\prime} 2 \%$. Ni siquiera añadiendo 1.566 votos a otros candidatos, además de los cuatro que se citan en el escrutinio, se alcanzan los resultados "oficiales". La única explicación es algún tipo de error en el cómputo de votos o votantes. En nuestro cómputo, que da un número ligeramente superior de votos y votantes (véase los totales del cuadro 3), los porcentajes se ajustan mucho más. 


\section{Cuadro 2: Votos obtenidos por las distintas candidaturas y candidatos}

\begin{tabular}{|c|c|c|c|c|c|c|c|c|}
\hline Frente Popular & Votos & $\%$ & Derechas & Votos & $\%$ & Otros & Votos & $\%$ \\
\hline Esplá (IR) & 131.274 & 53,6 & $\begin{array}{l}\text { Chapaprieta } \\
\text { (PRI) }\end{array}$ & 113.875 & 46,5 & $\begin{array}{l}\text { Senante } \\
\text { (CT) }\end{array}$ & 9.926 & 0,5 \\
\hline Gomáriz (UR) & 131.139 & 53,6 & $\begin{array}{l}\text { Torres } \\
\text { (CEDA) }\end{array}$ & 111.026 & 45,3 & $\begin{array}{l}\text { Oarrichena } \\
\text { (Rep. Rad.) }\end{array}$ & 4.322 & 0,2 \\
\hline Cremades (IR) & 131.059 & 53,5 & $\begin{array}{l}\text { Escolano } \\
\text { (CEDA) }\end{array}$ & 110.974 & 45,3 & $\begin{array}{c}\text { M.Arenas } \\
\text { (Conser- } \\
\text { vador) }\end{array}$ & 763 & 0,0 \\
\hline Llopis (PSOE) & 130.470 & 53,3 & $\begin{array}{l}\text { Canalejas } \\
\text { (PCD) }\end{array}$ & 110.112 & 45,0 & $\begin{array}{l}\text { G.Ramos } \\
\text { (Soc. inde) }\end{array}$ & 596 & 0,0 \\
\hline Ganga (PSOE) & 129.972 & 53,1 & $\begin{array}{l}\text { Alberola } \\
\text { (CEDA) }\end{array}$ & 110.006 & 44,9 & & & \\
\hline G.Serrano (IR) & 129.905 & 53,1 & $\begin{array}{l}\text { S. Navarro } \\
\text { (CEDA) }\end{array}$ & 107.255 & 43,8 & & & \\
\hline Villalta (PSOE) & 129.596 & 52,9 & $\begin{array}{c}\text { Cámara } \\
\text { (PCD) }\end{array}$ & 106.777 & 43,6 & & & \\
\hline Muñoz (PSOE) & 129.397 & 52,8 & $\begin{array}{l}\text { M. de León } \\
\text { (Independ.) }\end{array}$ & 102.870 & 42,0 & & & \\
\hline Voto medio & 130.352 & 53,2 & $\begin{array}{l}\text { Voto } \\
\text { medio }\end{array}$ & 109.224 & 44,5 & & & \\
\hline Voto total & 1.042 .812 & $54,0^{*}$ & Total & 873.795 & $45,2^{*}$ & Total & 15.657 & $0,8^{*}$ \\
\hline
\end{tabular}

Fuente: Acta del Escrutinio Oficial, Junta Provincial Electoral. AHDPA.

Votos blanco: 159. Votos nulos: 3.

* Notar la falta de coincidencia entre los porcentajes.

En cualquier caso, no cabe discutir la validez del resultado final. No se hizo entonces a lo largo del escrutinio oficial con muy pocas incidencias ni en la prensa y tampoco por las fuerzas políticas alicantinas. El triunfo del Frente Popular en primera vuelta le dio los ocho escaños en disputa por las mayorías y los tres de la minoría fueron adjudicados a los tres candidatos con mayor número de votos de la Derecha. En cuanto a la adscripción política de los nuevos diputados, cuatro pertenecían al PSOE (Llopis, Villalta, Ganga y García Muñoz), tres a Izquierda Republicana (Esplá, Cremades y Gómez Serrano) y uno a Unión Republicana (Gomáriz). En el campo de la derecha los tres diputados pertenecían uno al Partido Republicano Independiente (Chapaprieta) y los otros dos a la CEDA (Juan Torres y Eusebio Escolano).

En términos comparativos (no nos es posible entrar en la discusión acerca de las discrepancias de cifras), puede decirse que la provincia de Alicante se 
situó también ligeramente más a la izquierda que la media nacional, donde los resultados fueron más reñidos. En todo el Estado la candidatura del Frente Popular incluyendo el Front d'Esquerres en Cataluña obtuvo el 47'03\%, mientras en la provincia de Alicante conseguía el $54^{\prime} 0 \%$; las derechas obtenían en el Estado el 46'4\% frente al 45'2\% en Alicante.

De los resultados de la votación expresados en el cuadro II se puede observar la enorme disciplina electoral, especialmente en el caso del Frente Popular. Sólo 1.877 separan al más y menos votado de la candidatura lo que daría siguiendo la fórmula de Linz, un índice de indisciplina muy bajo de 0'01440 (1'4 de cada 100 votantes). Menor disciplina se observa en los votantes de las derechas, donde la diferencia fue de 4.651 votos y el índice de indisciplina de 0'042 (4'2 de cada 100). Es decir que la indisciplina electoral de las derechas triplicó a la de izquierdas, pues mientras 1'4\% votantes de la izquierda no votaron la candidatura completa y lo hicieron a otros candidatos, en el caso de la derecha fue de $42 \%$ de sus votantes.

Por último, expresar nuestro convencimiento de la futilidad de cualquier extrapolación de los resultados en términos partidistas de izquierdas, centro y derechas. De entrada no hubo en Alicante una candidatura de centro que concurriera como tal; en consecuencia, no podemos saber el apoyo electoral real $y$, dado el bajo nivel de indisciplina tampoco se pueden sacar conclusiones de las pequeñas diferencias de votos entre centristas y los candidatos más de derechas. En el caso de Alicante, lo más significativo es señalar que un candidato al que podríamos considerar en términos partidistas de centro, Joaquín Chapaprieta fue el más votado en la candidatura de las derechas, obteniendo 2.800 votos más que el segundo más votado. Pero pudo deberse también a la notoriedad o popularidad del personaje. En el caso de las izquierdas los tres candidatos más votados fueron de filiación republicana de izquierdas. La diferencia entre el republicano con más votos y el socialista con más votos fue de 837 votos. Poco más allá puede decirse en unas elecciones donde primó la disciplina de coalición sobre la disciplina de partidos y las posibles preferencias individuales de los votantes.

En cuanto a la distribución geográfica del voto en las comarcas alicantinas, en el cuadro 3 se muestran los resultados más relevantes:

Una primera precisión se refiere a pequeñas discrepancias en el escrutinio. Si lo referimos a los votos medios es de 149 votos más los computados por noso-

40. La fórmula aportada por Linz es: Indice Indisciplina sería el resultado de multiplicar el número de candidatos por la diferencias entre el más votado y menos votado de la candidatura. El resultado se divide por el número de votos totales obtenidos por la candidatura. 


\section{Cuadro 3: Resultados elecciones del Frente Popular en Alicante por comarcas}

\begin{tabular}{|l|r|r|r|r|r|r|r|r|r|}
\hline \multicolumn{1}{|c|}{$\begin{array}{c}\text { Totales } \\
\text { comarcales }\end{array}$} & $\begin{array}{c}\text { Frente } \\
\text { Popular } \\
\text { Votos } \\
\text { totales }\end{array}$ & $\begin{array}{c}\text { Frente } \\
\text { Popular } \\
\text { Votos } \\
\text { medios }\end{array}$ & $\begin{array}{c}\text { Frente } \\
\text { Popular } \\
\%\end{array}$ & $\begin{array}{r}\text { Derechas } \\
\text { Votos } \\
\text { totales }\end{array}$ & $\begin{array}{r}\text { Derechas } \\
\text { Votos } \\
\text { medios }\end{array}$ & $\begin{array}{r}\text { Derechas } \\
\%\end{array}$ & $\begin{array}{r}\text { Otros } \\
\text { Votos } \\
\text { Totales }\end{array}$ & $\begin{array}{c}\text { Otros } \\
\%\end{array}$ & Blanco \\
\hline Vega Baja & 123.836 & 15.480 & 36,5 & 212.304 & 26.538 & 62,5 & 3.424 & 1,0 & 2 \\
\hline Bajo Vinalopó & 114.083 & 14.260 & 59,2 & 77.677 & 9.710 & 40,3 & 832 & 0,4 & 1 \\
\hline Medio Vinalopó & 129.269 & 16.159 & 53,5 & 108.520 & 13.565 & 44,9 & 3.719 & 1,5 & 6 \\
\hline Alto Vinalopó & 65.287 & 8.161 & 60,4 & 42.517 & 5.315 & 39,3 & 273 & 0,3 & 5 \\
\hline Alacantí & 287.374 & 35.922 & 77,6 & 80.959 & 10.120 & 21,9 & 2.040 & 0,6 & 44 \\
\hline L'Alcoià & 127.631 & 15.954 & 58,5 & 87.738 & 10.967 & 40,2 & 2.667 & 1,2 & 39 \\
\hline El Comtat & 45.956 & 5.745 & 46,2 & 53.218 & 6.652 & 53,5 & 296 & 0,3 & 3 \\
\hline Marina Baixa & 57.370 & 7.171 & 46,5 & 64.555 & 8.069 & 52,3 & 1.473 & 1,2 & 1 \\
\hline Marina Alta & 93.199 & 11.650 & 38,4 & 146.750 & 18.344 & 60,5 & 2.549 & 1,1 & 6 \\
\hline Total & 1.044 .005 & 130.501 & 53,9 & 874.238 & 109.280 & 45,2 & 17.273 & 0,9 & 107 \\
\hline
\end{tabular}

Fuente: Elaboración propia a partir del Acta Escrutinio Oficial, Junta Provincial Electoral y Boletín Oficial Provincia de Alicante (BOPA).

Votos nulos: 3 en la Vega Baja

tros respecto al oficial en el caso del Frente Popular y 56 votos también más en el caso de la derecha. En ambos casos apenas tienen repercusión más que en una décima en el resultado. En el caso de "Otros", el Escrutinio Oficial no llegó a computar unos restos de votos de personajes de lo más diverso, tanto nacionales o locales, lo cual explica la diferencia de 1.566 votantes más en nuestro cómputo. Sólo como curiosidad, José Antonio Primo de Rivera recibió 207 votos.

En cuanto a la distribución del voto, en cinco comarcas ganó el Frente Popular y en cuatro la Derecha. Sin discusión, el triunfo del Frente Popular recibió su apoyo más masivo en los valles industriales del Alto, Medio y Bajo Vinalopó y también muy especialmente por el espectacular resultado de l'Alacantí donde el peso de la ciudad de Alicante es evidente. También es de destacar el triunfo en la comarca industrial alcoyana. Las comarcas más agrícolas de población más dispersa, como eran las de la montaña interior en el caso del Comtat y de las Marinas, así como el tradicional bastión agrícola, católico y conservador de la Vega Baja, fueron las que registraron el mayor apoyo a las derechas.

El resultado, de cualquier forma, pone en evidencia la división en dos bloques de la sociedad alicantina, al igual que el resto de la española, si bien la votación en la provincia se encuentra ligeramente más escorada a la izquierda, 
como lo fue durante todos los comicios en esta etapa en relación al marco nacional. Como se sabe, debido al sistema mayoritario a dos vueltas, pequeñas diferencias de votos, como el registrado en estas elecciones, podía traducirse en abultadas mayorías parlamentarias. En este caso, con una diferencia aproximada de 1,5 puntos porcentuales en votos en toda España, la izquierda obtendría el $60 \%$ de los escaños en las Cortes españolas ${ }^{41}$. En el caso de la provincia que analizamos, con una diferencia de $8^{7} 7$ puntos porcentuales en cuanto al voto, el Frente Popular se adjudicó el 72'7\% de los escaños en disputa.

En este triunfo del Frente Popular tuvo decisiva importancia la distinción entre el voto rural y urbano. Veamos las cifras en el siguiente cuadro.

\section{Cuadro 4: Voto urbano y voto rural.}

Distribución del voto en los ocho municipios más poblados y el resto

\begin{tabular}{|l|l|l|l|l|c|c|c|c|c|c|}
\hline & Población & Electores & Votantes & $\begin{array}{c}\text { Parti- } \\
\text { cipa- } \\
\text { ción }\end{array}$ & $\begin{array}{c}\text { FP } \\
\text { Votos } \\
\text { medios }\end{array}$ & $\begin{array}{c}\text { FP } \\
\%\end{array}$ & $\begin{array}{c}\text { Derecha } \\
\text { Votos } \\
\text { medios }\end{array}$ & $\begin{array}{c}\text { Derecha } \\
\%\end{array}$ & Otros & $\begin{array}{c}\text { Otros } \\
\%\end{array}$ \\
\hline $\begin{array}{l}\text { Municipios } \\
\text { grandes }\end{array}$ & 241.018 & 141.689 & 108.742 & 76,7 & 70.008 & 64,4 & 36.276 & 33,4 & 6.263 & 0,7 \\
\hline $\begin{array}{c}\text { Municipios } \\
\text { pequeños }\end{array}$ & 312.137 & 187.249 & 136.621 & 73,3 & 60.437 & 44,2 & 72.916 & 53,4 & 10.987 & 1,0 \\
\hline
\end{tabular}

Fuente: Elaboración a partir del Acta Escrutinio Oficial, Junta Provincial Electoral. AHDA.

Votos nulos 3 en la Vega Baja

En las ocho ciudades más grandes de la provincia, que representaban el 43’42\% de la población provincial el resultado para el Frente Popular fue de un 64'4\% del voto, frente al $442 \%$ de los votos en el resto de municipios menores. Y a la inversa, en los municipios pequeños la Derecha recibió mayoría absoluta de votos, el 53 '4\%. El desglose del voto en los ocho mayores municipios de la provincia la podemos observar en el cuadro 5 .

Como se puede apreciar de manera más detallada en este cuadro, excepto en Orihuela y Monóvar en donde ganaron las derechas, el resto votó mayoritariamente al Frente Popular, destacando especialmente el triunfo en la capital provincial donde obtuvo un aplastante $807 \%$ de los votos. Hay que destacar también la alta participación y el rotundo triunfo de la coalición de izquierdas en Alcoy y Elda, poblaciones de influencia libertaria.

41. PAYNE, Stanley G., El colapso de la República. Los orígenes de la Guerra Civil (1933-1936), Madrid, Esfera de los Libros, 2005, pp. 273 y ss. 
Cuadro 5: Resultados en los mayores municipios de la provincia de Alicante

\begin{tabular}{|l|c|c|c|c|c|c|c|c|}
\hline $\begin{array}{l}\text { Mayores } \\
\text { municipios }\end{array}$ & Población & $\begin{array}{c}\text { Participa- } \\
\text { pación }\end{array}$ & $\begin{array}{c}\text { FP } \\
\text { Votos } \\
\text { totales }\end{array}$ & $\begin{array}{c}\text { FP } \\
\text { Votos } \\
\text { medios }\end{array}$ & $\begin{array}{c}\text { Derechas } \\
\text { Votos } \\
\text { totales }\end{array}$ & $\begin{array}{c}\text { Derechas } \\
\text { Votos } \\
\text { medios }\end{array}$ & $\begin{array}{c}\text { Frente } \\
\text { Popular } \\
\%\end{array}$ & $\begin{array}{c}\text { Derechas } \\
\%\end{array}$ \\
\hline Alicante & 72.474 & 76,5 & 217.097 & 27.137 & 50.547 & 6.318 & 80,7 & 18,8 \\
\hline Alcoy & 39.002 & 82,5 & 102.497 & 12.812 & 48.625 & 6.078 & 67,3 & 31,9 \\
\hline Orihuela & 38.712 & 69,3 & 27.083 & 3.385 & 72.403 & 9.050 & 26,5 & 70,9 \\
\hline Elche & 36.995 & 80,1 & 87.811 & 11.043 & 53.339 & 6.778 & 62,1 & 37,7 \\
\hline Villena & 17.250 & 76,1 & 42.874 & 5.359 & 21.792 & 2.724 & 66,2 & 33,6 \\
\hline Denia & 13.286 & 66,5 & 27.462 & 3.433 & 12.372 & 1.547 & 67,9 & 30,6 \\
\hline Elda & 13.268 & 78,9 & 37.402 & 4.675 & 11.477 & 1.435 & 76,4 & 23,4 \\
\hline Monóvar & 10.031 & 78,8 & 18.284 & 2.286 & 20.354 & 2.544 & 47,3 & 52,7 \\
\hline Totales & 241.018 & 76,7 & 560.510 & 70.008 & 290.909 & 36.276 & 64,4 & 33,4 \\
\hline
\end{tabular}

Fuente: Elaboración a partir del Acta Escrutinio Oficial, Junta Provincial Electoral. AHDPA

El escrutinio transcurrió entre los días 16 y 19 de febrero con escasísimas incidencias, mientras un auténtico terremoto político sacudía la sociedad española ${ }^{42}$. El día 19, ante el vacío de poder creado por la huída de Portela Valladares, Azaña formó gobierno saltándose todos los plazos constitucionales. Al día siguiente, se producían en Alicante y otras ciudades de la provincia gravísimos disturbios. El triunfo del Frente Popular, como anotaba el propio Azaña en sus diarios comenzaba con "chamusquinas" y nuevamente había que "segar el trigo en verde ${ }^{43}$.

\section{Conclusiones}

Como se indicaba en la introducción, la abundancia de fuentes para el estudio provincial nos ha permitido conocer a través de las fuentes primarias directas los resultados electorales y algunas de las claves básicas del comportamiento electoral de la ciudadanía. Había ciertas tradiciones electorales ya consolidadas como el peso del voto agrario en unas comarcas (Vega Baja y las Marinas)

42. Las únicas incidencias del escrutinio fueron la anulación del Acta del pequeño pueblo de Castell de Castells porque uno de los candidatos de la derecha había sacado más votos que votantes. Una mesa del primer distrito de Orihuela no se pudo computar al no haberse podido celebrar la votación. Finalmente, en La Vila se anularon 83 votos a los candidatos de la derecha.

43. Vid. en AZAÑA, Memorias, "Crónica de dos días", Madrid, Ed. Crítica, 1978, pp. 10-21. 
hacia posiciones conservadoras y el voto de las comarcas industriales de los valles del Vinalopó y de la capital provincia, ya tradicionalmente escorados a la izquierda. En estas elecciones esas tendencias se vieron reforzadas por la polarización política nacional que hizo movilizarse en la provincia hasta el voto digamos antipolítico del mundo libertario, como se ha visto claramente en los casos de Alcoy, Elda y La Vila. El peso del voto urbano explica también el triunfo del Frente Popular, aunque con una importante movilización del voto del centro-derecha que consigue mejorar sus resultados anteriores. Sorprende en comparación con otros distritos, la casi total ausencia de incidentes e incidencias electorales, por lo que para el caso alicantino pueden ser consideradas unas elecciones democráticas y limpias. Todo lo demás, el tremendo vuelco electoral que supuso, la conmoción social y política que produjo, la reacción de los principales agentes sociales y políticos, abriría una nueva etapa política, desgraciadamente aquella que conduciría al estallido de la guerra civil. Los peores presagios electorales acabaron cumpliéndose. De las razones, que son siempre las armas de la democracia, se pasó a los fusiles, a la fuerza, a la barbarie de la guerra. 


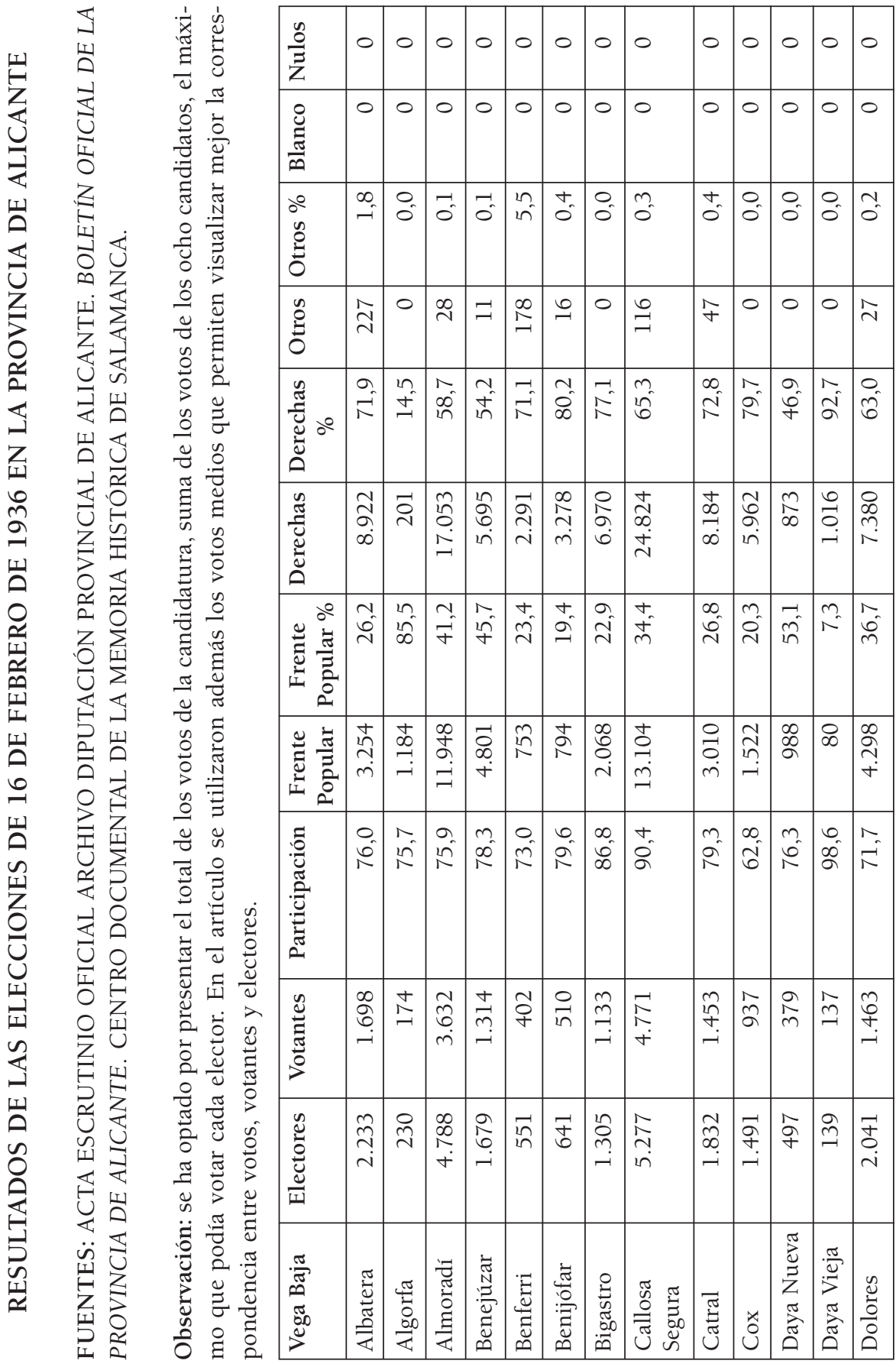




\begin{tabular}{|c|c|c|c|c|c|c|c|c|c|c|c|c|c|}
\hline$\frac{n}{\stackrel{n}{3}}$ & 0 & 0 & 0 & 0 & $m$ & 0 & 0 & 0 & 0 & 0 & 0 & 0 & $m$ \\
\hline 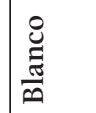 & 0 & 0 & - & 0 & 0 & 0 & 0 & 0 & $\neg$ & 0 & 0 & 0 & $\mathrm{~N}$ \\
\hline $\begin{array}{l}0 \\
0 \\
0 \\
0 \\
0\end{array}$ & 0 & 0 & 0 & 0 & $\begin{array}{l}0 \\
i\end{array}$ & $\begin{array}{l}0 \\
0\end{array}$ & $\begin{array}{l}0 \\
0\end{array}$ & $\overrightarrow{0}$ & $\tilde{n}^{n}$ & $\tilde{0}$ & $0^{\circ}$ & $\overrightarrow{0}$ & $\stackrel{\circ}{\circ}$ \\
\hline$\stackrel{\mathscr{0}}{0}$ & 10 & 0 & 0 & 0 & 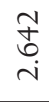 & 0 & -1 & \pm & in & 그 & 0 & $\stackrel{m}{f}$ & 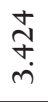 \\
\hline 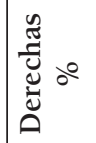 & $\begin{array}{l}m \\
\infty \\
\infty\end{array}$ & $\overrightarrow{0}$ & $\begin{array}{l}n \\
0\end{array}$ & 0 & $\hat{0}$ & $\begin{array}{l}0 \\
\text { in }\end{array}$ & má & $\hat{n}$ & î & $\hat{a}$ & $\stackrel{\sim}{i n}$ & 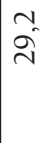 & $\tilde{\tilde{\sigma}}$ \\
\hline 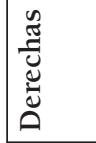 & $\begin{array}{l}\stackrel{2}{\mathcal{T}} \\
\stackrel{+}{+}\end{array}$ & $\begin{array}{l}m \\
\infty \\
0 \\
1 \\
\end{array}$ & $\begin{array}{l}\stackrel{\infty}{\infty} \\
\stackrel{+}{+} \\
\dot{m}\end{array}$ & $\begin{array}{l}\text { ț } \\
\text { in } \\
\text { r }\end{array}$ & $\begin{array}{l}\hat{o} \\
+ \\
i \\
N\end{array}$ & $\underset{6}{\mathbb{N}}$ & $\begin{array}{l}\infty \\
\infty \\
\infty \\
\sim \\
\sim\end{array}$ & $\begin{array}{l}\text { oे } \\
\text { mे } \\
\text { in }\end{array}$ & $\begin{array}{l}\stackrel{n}{f} \\
\stackrel{i}{N}\end{array}$ & $\stackrel{N}{n}$ & $\begin{array}{l}\stackrel{0}{r} \\
\stackrel{R}{r}\end{array}$ & $\begin{array}{l}+ \\
\infty \\
0 \\
\sigma \\
\sigma\end{array}$ & 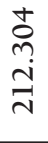 \\
\hline 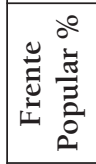 & $\hat{m}$ & $\hat{a}$ & $\hat{\tilde{v}}$ & 0 & $\begin{array}{l}n \\
\text { in } \\
\text { ? }\end{array}$ & $\begin{array}{l}0 \\
\sim\end{array}$ & $\hat{\tilde{\rho}}$ & $\begin{array}{l}+ \\
\dot{\sigma}\end{array}$ & $\stackrel{\infty}{m}$ & $\begin{array}{l}\infty \\
\text { in }\end{array}$ & $\begin{array}{l}\infty \\
\dot{J}\end{array}$ & $\begin{array}{l}0 \\
0 \\
0\end{array}$ & $\begin{array}{l}\hat{n} \\
\hat{n}^{\prime}\end{array}$ \\
\hline 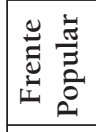 & $\stackrel{t}{0}$ & $\begin{array}{l}0 \\
\text { ơ } \\
0 \\
\end{array}$ & 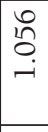 & רִ & $\begin{array}{l}0 \\
\infty \\
0 \\
\text { N } \\
\text { N }\end{array}$ & $\stackrel{+}{\sim}$ & $\begin{array}{l}\stackrel{\circ}{\sim} \\
\stackrel{-}{\sim}\end{array}$ & $\begin{array}{l}\infty \\
\delta \\
\varnothing \\
+\end{array}$ & 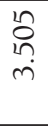 & $\begin{array}{l}\text { No } \\
\text { O } \\
\text { i }\end{array}$ & $\begin{array}{l}\stackrel{8}{ } \\
\text { nִ }\end{array}$ & $\begin{array}{l}\vec{\sigma} \\
\hat{n} \\
\hat{\sim}\end{array}$ & $\begin{array}{l}0 \\
\infty \\
\infty \\
\\
\end{array}$ \\
\hline 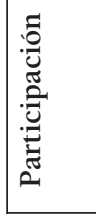 & $\hat{\infty}$ & $\frac{N}{N}$ & $\stackrel{\sim}{n}$ & $\frac{\sigma^{2}}{N}$ & $\hat{b}$ & 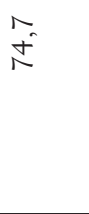 & $\begin{array}{l}+ \\
\infty \\
\infty\end{array}$ & 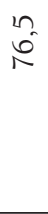 & $\begin{array}{l}\infty \\
\infty \\
\infty\end{array}$ & $\stackrel{\text { N }}{\text { 足 }}$ & $\underset{⿱ 亠 幺}{N}$ & 点 & $\stackrel{10}{n}$ \\
\hline 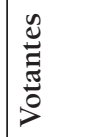 & $\underset{\mathfrak{Z}}{\mathcal{Z}}$ & 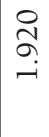 & 旾 & $\stackrel{+}{\infty}$ & $\begin{array}{l}\vec{\rho} \\
\tilde{n} \\
\dot{\sigma}\end{array}$ & $\underset{\Xi}{\beth}$ & $\underset{n}{n}$ & 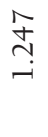 & $\begin{array}{l}m \\
\stackrel{n}{\sim} \\
\stackrel{n}{-}\end{array}$ & $\stackrel{+}{+}$ & $\frac{1}{6}$ & 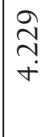 & $\begin{array}{l}\stackrel{+}{o} \\
\dot{m} \\
\dot{f}\end{array}$ \\
\hline 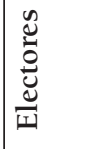 & $\underset{N}{\stackrel{\Delta}{N}}$ & $\begin{array}{l}\stackrel{r}{\infty} \\
\stackrel{\infty}{+} \\
\sim\end{array}$ & $\frac{R}{N}$ & $\stackrel{\imath}{\sigma}$ & 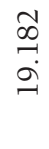 & 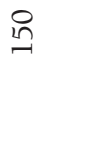 & $\hat{\sigma}$ & $\stackrel{\vec{\sigma}}{\vec{\sigma}}$ & $\begin{array}{l}\mathfrak{n} \\
\stackrel{n}{\mathfrak{n}} \\
\end{array}$ & $\underset{\infty}{\infty}$ & $\underset{\infty}{\infty}$ & 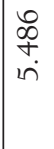 & $\begin{array}{l}\text { gे } \\
\text { in } \\
\text { in }\end{array}$ \\
\hline 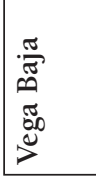 & 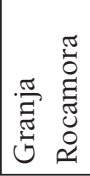 & 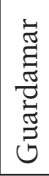 & 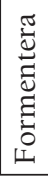 & 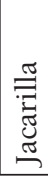 & 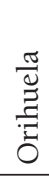 & 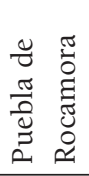 & $\begin{array}{l}\frac{\pi}{\pi} \\
\widetilde{\pi} \\
\end{array}$ & 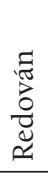 & $\frac{\tilde{u}}{\frac{\pi}{2}}$ & 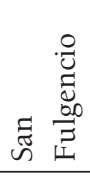 & 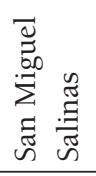 & 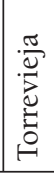 & $\stackrel{\pi}{0}$ \\
\hline
\end{tabular}

Pasado y Memoria. Revista de Historia Contemporánea, 11, 2012, pp. 205-238 


\begin{tabular}{|c|c|c|c|c|c|c|c|c|c|c|c|c|c|c|c|c|c|c|}
\hline$\frac{n}{5}$ & 0 & 0 & 0 & 0 & : & $\frac{n}{3}$ & 0 & 0 & 0 & 0 & 0 & 0 & 0 & 0 & 0 & 0 & 0 & 0 \\
\hline$\frac{8}{\Xi}$ & -1 & 0 & 0 & -1 & 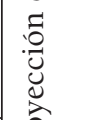 & $\frac{8}{0}$ & 0 & 0 & $m$ & 0 & 0 & 0 & 0 & -1 & $\sim$ & 0 & 0 & 0 \\
\hline $\begin{array}{l}0 \\
\text { in } \\
0 \\
0 \\
0\end{array}$ & 0 & $\overrightarrow{0}$ & $\stackrel{m}{i}$ & $\stackrel{+}{0}$ & $\begin{array}{l}\vec{\Xi} \\
\stackrel{\vec{a}}{\Xi}\end{array}$ & ô & $\begin{array}{l}0 \\
0^{\prime}\end{array}$ & \begin{tabular}{c|}
0 \\
$m$
\end{tabular} & $\begin{array}{l}\text { N } \\
0\end{array}$ & $\begin{array}{l}n \\
0 \\
0\end{array}$ & \begin{tabular}{l}
$\mathcal{N}$ \\
\multirow{r}{*}{}
\end{tabular} & $\begin{array}{l}m \\
0\end{array}$ & $\begin{array}{l}0 \\
0\end{array}$ & $\vec{i}$ & $\begin{array}{l}\hat{i n} \\
\end{array}$ & $\begin{array}{l}0 \\
0 \\
0\end{array}$ & $\Rightarrow$ & 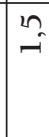 \\
\hline o̊ & ळे & $\stackrel{\infty}{\infty}$ & $\underset{\sim}{\sim}$ & $\underset{\infty}{\sim}$ & 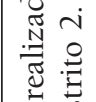 & O̊. & $N$ & 亲 & ๙ & $\begin{array}{l}0 \\
i n\end{array}$ & 8 & $\stackrel{F}{F}$ & $\stackrel{\infty}{-1}$ & $\begin{array}{l}n \\
\infty \\
\infty\end{array}$ & $\begin{array}{c}\stackrel{+}{m} \\
\stackrel{\sim}{\sim}\end{array}$ & $\sim$ & $a$ & $\begin{array}{l}\hat{\sigma} \\
\dot{n}\end{array}$ \\
\hline 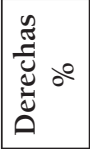 & $\begin{array}{l}0 \\
\infty \\
+\end{array}$ & $\hat{n}$ & $\stackrel{n}{\tilde{r}}$ & $\begin{array}{l}m \\
\dot{f}\end{array}$ & 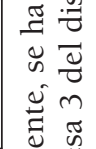 & 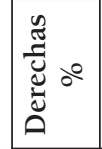 & $\vec{n}$ & $\begin{array}{l}a \\
\hat{f}\end{array}$ & $\begin{array}{l}\dot{v} \\
\tilde{v}\end{array}$ & $\begin{array}{c}0 \\
i n \\
\text { in }\end{array}$ & $\begin{array}{l}0 \\
\hat{\sigma}\end{array}$ & $\begin{array}{l}\infty \\
\mathfrak{f} \\
\mathcal{f}\end{array}$ & $\begin{array}{l}\hat{n} \\
\text { in }\end{array}$ & $\begin{array}{c}0 \\
\tilde{F}\end{array}$ & $\begin{array}{c}0 \\
\hat{m} \\
\end{array}$ & $\begin{array}{c}0 \\
n \\
N\end{array}$ & $\begin{array}{l}n \\
\text { in }\end{array}$ & $\begin{array}{l}\sigma \\
f\end{array}$ \\
\hline 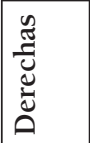 & $\begin{array}{l}\overrightarrow{\tilde{b}} \\
\dot{a}\end{array}$ & $\begin{array}{l}\hat{\tilde{m}} \\
\hat{n} \\
\hat{n}\end{array}$ & \begin{tabular}{l}
\multirow{2}{*}{} \\
+
\end{tabular} & 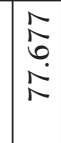 & 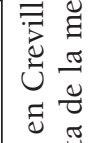 & 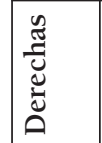 & $\begin{array}{l}\tilde{N} \\
\tilde{m} \\
\tilde{m}\end{array}$ & 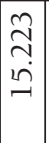 & 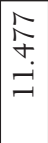 & 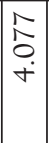 & 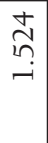 & $\begin{array}{l}\text { त̂ } \\
\stackrel{2}{n} \\
\text { in }\end{array}$ & 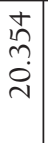 & \begin{tabular}{l|l}
0 \\
$\infty$ \\
$\infty$ \\
1 \\
\\
\end{tabular} & \begin{tabular}{l}
\multirow{2}{n}{} \\
กิ \\
\end{tabular} & 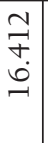 & \begin{tabular}{|c|}
8 \\
8 \\
in \\
\end{tabular} & $\begin{array}{l}0 \\
\text { กิ } \\
\infty \\
0 \\
0\end{array}$ \\
\hline 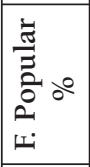 & 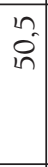 & तु & $\begin{array}{l}m \\
\text { in }\end{array}$ & กิ & 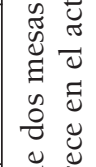 & 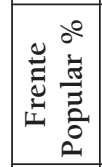 & $\begin{array}{l}a \\
b \\
t\end{array}$ & \begin{tabular}{|l|}
$\vec{q}$ \\
$\dot{q}$
\end{tabular} & $\begin{array}{l}+ \\
0 \\
0\end{array}$ & $\begin{array}{l}\infty \\
\vec{f} \\
\end{array}$ & $\begin{array}{l}m \\
\hat{n}\end{array}$ & $\begin{array}{l}a \\
\hat{b}^{\prime} \\
\hat{n}^{2}\end{array}$ & $\begin{array}{l}m \\
\mathcal{f} \\
+\end{array}$ & $\begin{array}{l}\text { ma } \\
\dot{\text { in }}\end{array}$ & $\begin{array}{l}\hat{0} \\
\hat{D}^{\prime}\end{array}$ & \begin{tabular}{c}
0 \\
\multirow{2}{N}{} \\
\end{tabular} & $\begin{array}{l}+ \\
\dot{f} \\
\stackrel{f}{*}\end{array}$ & $\begin{array}{l}n \\
\hat{n} \\
\end{array}$ \\
\hline 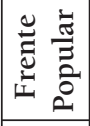 & $\begin{array}{l}\hat{a} \\
\text { n. } \\
\hat{\imath}\end{array}$ & $\begin{array}{l}\exists \\
\infty \\
\infty \\
\infty\end{array}$ & $\begin{array}{l}n \\
\infty \\
\infty \\
i n\end{array}$ & $\begin{array}{l}m \\
\infty \\
0 \\
\dot{+} \\
\beth \\
-1\end{array}$ & 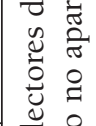 & 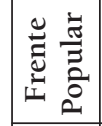 & $\begin{array}{l}+ \\
\text { ने } \\
\text { ì }\end{array}$ & $\begin{array}{l}8 \\
8 \\
0 \\
10 \\
1\end{array}$ & 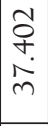 & \begin{tabular}{|l|}
$\overrightarrow{0}$ \\
$m$ \\
$m$ \\
$m$
\end{tabular} & $\frac{⿱}{N}$ & 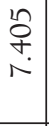 & 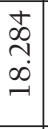 & 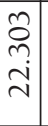 & $\begin{array}{l}\text { 華 } \\
\text { ñ. } \\
=\end{array}$ & 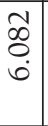 & 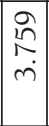 & 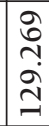 \\
\hline 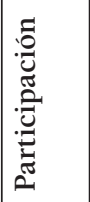 & $\stackrel{n}{\infty}$ & $\overrightarrow{8}$ & $\begin{array}{l}0 \\
\text { in }\end{array}$ & $\begin{array}{l}0 \\
\infty \\
\infty\end{array}$ & 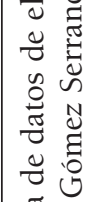 & 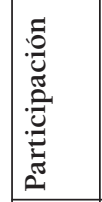 & 点 & \begin{tabular}{|c|}
-1 \\
$\tilde{s}$ \\
$\infty$
\end{tabular} & $\begin{array}{l}a \\
\infty \\
\infty\end{array}$ & \begin{tabular}{l}
$n$ \\
\multirow{t}{0}{}
\end{tabular} & $\hat{\sigma}$ & $\begin{array}{l}m \\
\tilde{s}^{\prime}\end{array}$ & $\begin{array}{l}\infty \\
\infty \\
\infty \\
1\end{array}$ & $\begin{array}{l}m \\
\text { กิ } \\
\infty\end{array}$ & $\begin{array}{l}+ \\
\stackrel{+}{N}\end{array}$ & $\begin{array}{l}\infty \\
i \\
N\end{array}$ & $\begin{array}{l}-1 \\
N\end{array}$ & $\begin{array}{c}m \\
\infty \\
\infty\end{array}$ \\
\hline 萭 & $\begin{array}{c}\infty \\
0 \\
\stackrel{1}{1} \\
i\end{array}$ & $\begin{array}{l}\infty \\
\infty \\
\infty \\
1 \\
-1\end{array}$ & 훙 & $\begin{array}{l}\stackrel{n}{m} \\
\stackrel{ \pm}{\sim}\end{array}$ & 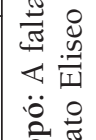 & 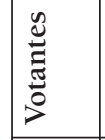 & $\begin{array}{l}+ \\
\\
\infty\end{array}$ & 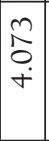 & $\begin{array}{l}0 \\
\frac{1}{6} \\
0\end{array}$ & নু & $\stackrel{\text { }}{\text { m }}$ & $\begin{array}{l}0 \\
2 \\
0 \\
0 \\
-i\end{array}$ & $\begin{array}{l}n \\
\\
\infty \\
+ \\
\end{array}$ & $\begin{array}{l}\tilde{N} \\
\text { in } \\
\text { in }\end{array}$ & $\begin{array}{l}\stackrel{g}{a} \\
\grave{+} \\
\text { i }\end{array}$ & $\begin{array}{l}\infty \\
+ \\
\infty \\
ن\end{array}$ & $\begin{array}{ll}\infty \\
0 \\
ٍ \\
-1 \\
-1\end{array}$ & $\begin{array}{l}\tau \\
0 \\
\dot{m} \\
\dot{m}\end{array}$ \\
\hline 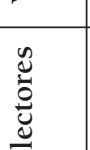 & 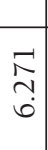 & 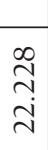 & $\begin{array}{l}\dot{m} \\
\dot{v} \\
\dot{v}\end{array}$ & $\begin{array}{l}\hat{n} \\
\dot{a} \\
\hat{m}\end{array}$ & 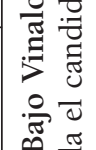 & 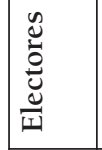 & $\begin{array}{c}1 \\
0 \\
\ddots \\
-1 \\
\end{array}$ & $\begin{array}{l}\vec{b} \\
2 \\
+\end{array}$ & 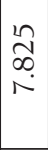 & $\begin{array}{c}\mathfrak{T} \\
\mathfrak{n} \\
i \\
\end{array}$ & $\frac{n n}{n}$ & $\begin{array}{l}\vec{b} \\
\vdots \\
i\end{array}$ & 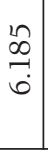 & 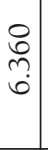 & $\begin{array}{l}\vec{b} \\
\text { m. } \\
m\end{array}$ & $\begin{array}{l}\stackrel{i}{N} \\
\dot{m}\end{array}$ & \begin{tabular}{|c}
$\hat{m}$ \\
$\stackrel{\sim}{\sim}$
\end{tabular} & 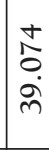 \\
\hline 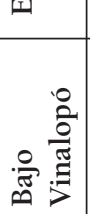 & 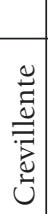 & $\frac{\tilde{T}}{\frac{\pi}{I I}}$ & 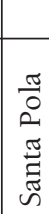 & స్ّ & 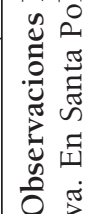 & 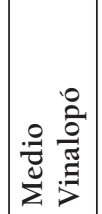 & 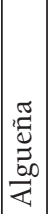 & $\mid \begin{array}{c}\tilde{a} \\
\frac{\vec{n}}{幺}\end{array}$ & $\frac{\frac{\pi}{6}}{\mid-1}$ & 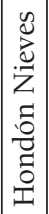 & 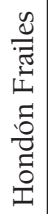 & 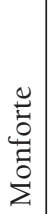 & 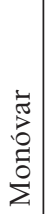 & $\begin{array}{l}\frac{\pi}{0} \\
0 \\
0 \\
z\end{array}$ & $\begin{array}{l}\bar{\Xi} \\
\stackrel{\Xi}{\Delta} \\
0\end{array}$ & $\begin{array}{l}0 \\
0 \\
0 \\
\vdots \\
\end{array}$ & 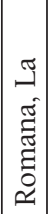 & 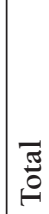 \\
\hline
\end{tabular}

Pasado y Memoria. Revista de Historia Contemporánea, 11, 2012, pp. 205-238 
菑

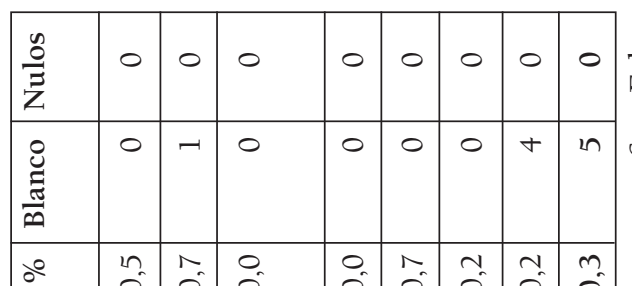

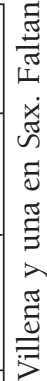

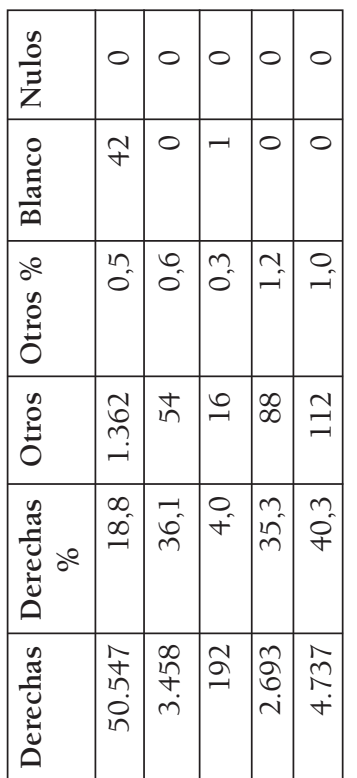

$\circ$

๙

픔

코

\% 든

$\stackrel{\circ}{\circ}$

\&

푱

巡

हี

을

응

क

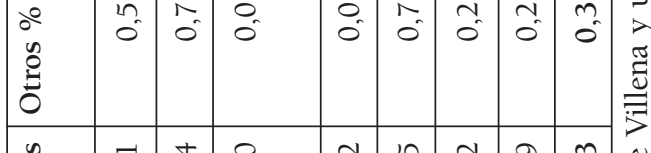

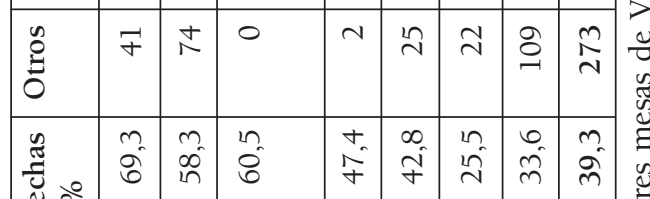

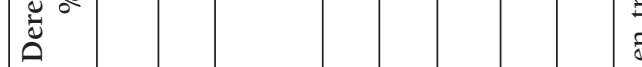

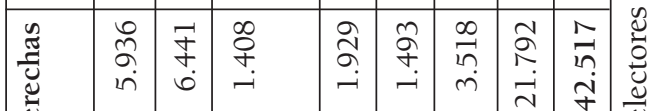

คั

艺

을

氠

봄

州

岛

घี

을

岳星

$\ddot{\circ}$

음

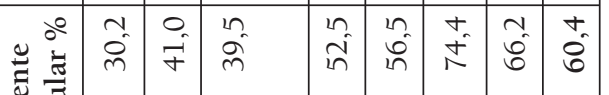

营

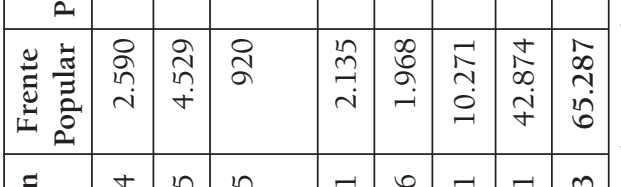

跣

בै:

$\approx$

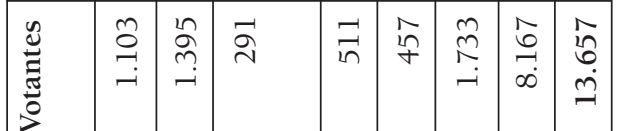

$\approx$ n

$\because$

$\sum_{0}^{\infty}$

ڤै

宽

เ

㲾

\begin{tabular}{|c|c|c|c|c|c|c|c|c|}
\hline 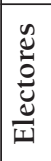 & 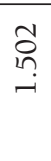 & $\begin{array}{l}\mathfrak{\Omega} \\
\text { ă } \\
-1\end{array}$ & o̊ & $\begin{array}{l}0 \\
0 \\
0\end{array}$ & 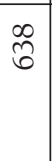 & $\begin{array}{l}\text { ભे } \\
\text { ஸे } \\
\text { i }\end{array}$ & $\begin{array}{l}\stackrel{2}{N} \\
\stackrel{0}{0}\end{array}$ & $\begin{array}{l} \pm \\
m \\
\infty \\
\infty\end{array}$ \\
\hline 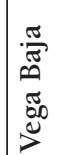 & 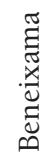 &.$\tilde{\pi}$ & 㣽 & $\left|\begin{array}{l}\tilde{J} \\
\tilde{\mathscr{Z}} \\
\tilde{J}\end{array}\right|$ & 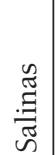 & 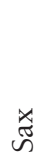 & 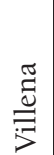 & 䒕 \\
\hline
\end{tabular}

\begin{tabular}{|c|c|c|c|c|}
\hline 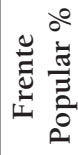 & $\hat{\infty}$ & $\tilde{\sigma}$ & $\begin{array}{l}0 \\
2 \\
\alpha\end{array}$ & $\begin{array}{l}n \\
\hat{\sigma}\end{array} \mid$ \\
\hline 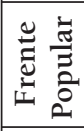 & \begin{tabular}{|l}
$\hat{a}$ \\
$\delta$ \\
\\
\\
\end{tabular} & $\begin{array}{l}\hat{n} \\
\hat{o} \\
0\end{array}$ & $\begin{array}{l}\infty \\
\tilde{n} \\
\\
+\end{array}$ & $\begin{array}{l}\stackrel{\rho}{\hat{\alpha}} \\
\infty \\
+\dot{+}\end{array}$ \\
\hline 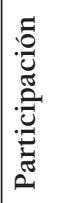 & $\begin{array}{l}n \\
0 \\
n\end{array}$ & $\hat{N}$ & $\stackrel{m}{\stackrel{m}{N}}$ & $\begin{array}{l}n \\
0 \\
0\end{array}$ \\
\hline 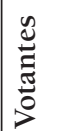 & $\begin{array}{l}\stackrel{\sim}{\sim} \\
\infty \\
\tilde{m}\end{array}$ & 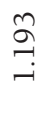 & in & 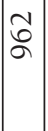 \\
\hline 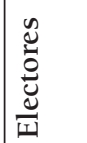 & 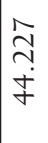 & 赵 & 8 & $\begin{array}{l}\infty \\
\stackrel{\infty}{2} \\
\stackrel{\sim}{\sim} \\
-1\end{array}$ \\
\hline 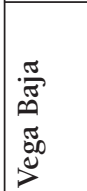 & 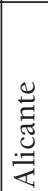 & $\begin{array}{l}\vec{w} \\
2_{0}^{\infty} \\
\infty \\
\infty\end{array}$ & 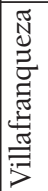 & 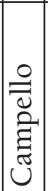 \\
\hline
\end{tabular}

Pasado y Memoria. Revista de Historia Contemporánea, 11, 2012, pp. 205-238 


\begin{tabular}{|c|c|c|c|c|c|c|c|c|c|c|c|c|c|c|c|c|c|c|}
\hline$\frac{n}{\frac{n}{3}}$ & 0 & 0 & 0 & 0 & 0 & 0 & 0 & : & $\frac{n}{0}$ & 0 & 0 & 0 & 0 & 0 & 0 & 0 & 0 & 0 \\
\hline$\frac{8}{0}$ & 0 & 0 & 0 & $\neg$ & 0 & 0 & F & ש్ర్జ & 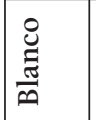 & $m$ & 0 & 0 & $\neg$ & $n$ & 0 & 0 & 0 & बे \\
\hline $\begin{array}{l}0 \\
0 \\
0 \\
0 \\
0\end{array}$ & $\hat{\imath}$ & $\tilde{O}$ & $\begin{array}{l}0 \\
0\end{array}$ & $\tilde{0}$ & $\begin{array}{l}0 \\
0\end{array}$ & ป̂. & 0 & $\begin{array}{l}\lambda \\
\stackrel{\lambda}{\Xi}\end{array}$ & $\begin{array}{l}00 \\
0 \\
0 \\
0 \\
0\end{array}$ & $\begin{array}{l}\infty \\
0\end{array}$ & $\hat{0}$ & $\dot{m}$ & $\hat{N}$ & $\overrightarrow{0}$ & $0^{\circ}$ & $\begin{array}{l}n \\
0\end{array}$ & 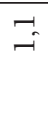 & $\stackrel{\sim}{-}$ \\
\hline$\stackrel{n}{0}$ & 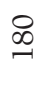 & I & 守 & $\stackrel{-}{\circ}$ & $\stackrel{9}{9}$ & $\infty$ & $\begin{array}{l}0 \\
\text { + } \\
\text { in } \\
\text { i }\end{array}$ & $\tilde{\pi}$ & $\stackrel{n}{0}$ & $\stackrel{n}{\stackrel{n}{\sim}}$ & $\infty$ & $\hat{\sigma}$ & $\stackrel{\sqrt[n]{ }}{\stackrel{n}{-}}$ & $\stackrel{-}{\circ}$ & in & ㄱ. & 壬 & $\begin{array}{l}\hat{0} \\
0 \\
i \\
i\end{array}$ \\
\hline 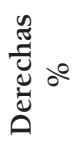 & $\overrightarrow{\tilde{N}}$ & $\begin{array}{l}0 \\
2\end{array}$ & $\stackrel{\sim}{\tilde{n}}$ & $\begin{array}{l}n \\
0 \\
n \\
m\end{array}$ & $\begin{array}{l}0 \\
10\end{array}$ & $\vec{m}$ & $\frac{a}{n}$ & $\begin{array}{l}\tilde{U} \\
\Xi \\
\tilde{\Xi} \\
0\end{array}$ & 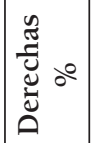 & $\vec{m}$ & $\begin{array}{l}0 \\
\infty \\
0 \\
0\end{array}$ & $\stackrel{m}{F}$ & $\begin{array}{l}\text { a } \\
\infty \\
i n\end{array}$ & $\begin{array}{l}m \\
8 \\
0\end{array}$ & ñ & 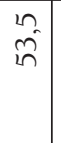 & $\begin{array}{l}n \\
\hat{0}\end{array}$ & $\tilde{f}$ \\
\hline 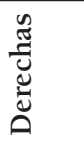 & 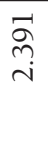 & $\begin{array}{l}\stackrel{\circ}{\circ} \\
\stackrel{\sigma}{\circ} \\
\end{array}$ & 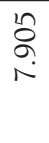 & \begin{tabular}{l}
8 \\
$\stackrel{8}{0}$ \\
\hdashline
\end{tabular} & $\begin{array}{l}\vec{\sigma} \\
\text { ָे }\end{array}$ & $\begin{array}{l}n \\
0 \\
0 \\
-1 \\
-1\end{array}$ & $\begin{array}{l}\hat{\sigma} \\
\hat{\alpha} \\
\hat{\delta} \\
\infty\end{array}$ & $\begin{array}{l}\stackrel{0}{0} \\
\stackrel{0}{0}\end{array}$ & 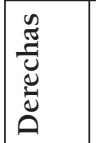 & $\begin{array}{l}\tilde{a} \\
b \\
\infty \\
+ \\
+\end{array}$ & $\begin{array}{l}N \\
\infty \\
\infty \\
\infty\end{array}$ & $\stackrel{\substack{n \\
N}}{2}$ & $\begin{array}{l}\stackrel{\text { Oे }}{+} \\
\text { ă }\end{array}$ & $\begin{array}{l}\stackrel{+}{+} \\
\text { å }\end{array}$ & $\begin{array}{l}\hat{8} \\
8 \\
0\end{array}$ & 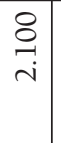 & $\stackrel{n}{\stackrel{n}{r}}$ & $\begin{array}{l}\infty \\
\stackrel{N}{N} \\
\stackrel{\infty}{\infty}\end{array}$ \\
\hline 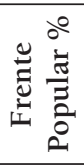 & $\hat{b}^{m}$ & $\infty$ & Ñ & $\hat{g}$ & $\hat{m}$ & t & $\begin{array}{l}0 \\
N \\
N\end{array}$ & 莺 & 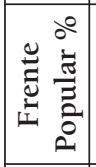 & $\stackrel{n}{6}$ & $\hat{O}$ & $\begin{array}{l}\overrightarrow{i n} \\
\text { in }\end{array}$ & $\stackrel{\dot{m}}{m}$ & $\begin{array}{l}0 \\
\text { ले }\end{array}$ & \begin{tabular}{l}
$\infty$ \\
\multirow{r}{+}{}
\end{tabular} & $\begin{array}{l}0 \\
\dot{0} \\
+\end{array}$ & $\stackrel{\dot{m}}{m}$ & $\begin{array}{l}n \\
\infty \\
i n\end{array}$ \\
\hline 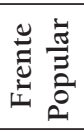 & $\begin{array}{l}\hat{b} \\
\sim \\
\infty\end{array}$ & $\begin{array}{l}n \\
\text { ôt } \\
0 \\
0\end{array}$ & $\begin{array}{l}+ \\
\stackrel{+}{+} \\
\dot{0}\end{array}$ & 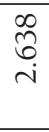 & $\begin{array}{l}\infty \\
\stackrel{0}{0} \\
\sim \\
-1\end{array}$ & $\begin{array}{l}8 \\
8 \\
i \\
\text { i }\end{array}$ & $\begin{array}{l}+ \\
\mathfrak{n} \\
\\
\infty \\
\end{array}$ & $\underset{\Xi}{\Xi}$ & 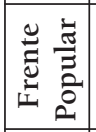 & \begin{tabular}{l}
$\hat{a}$ \\
q \\
a \\
0 \\
\cline { 1 - 1 }
\end{tabular} & $\begin{array}{l}\overrightarrow{6} \\
\text { ๙े } \\
\text { r. }\end{array}$ & $\begin{array}{l}\stackrel{+}{+} \\
0 \\
-1\end{array}$ & 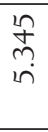 & $\begin{array}{l}8 \\
\infty \\
0 \\
0\end{array}$ & 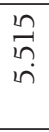 & $\begin{array}{l}\infty \\
0 \\
\infty \\
-i \\
-1\end{array}$ & $\stackrel{n}{\infty}$ & $\begin{array}{l}\vec{n} \\
\hat{\sigma} \\
\stackrel{1}{0}\end{array}$ \\
\hline 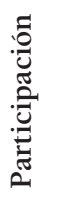 & $\stackrel{\sim}{N}$ & $\stackrel{0}{0}$ & $\stackrel{a}{i}$ & $\stackrel{n}{N}$ & $\begin{array}{l}\infty \\
\Omega\end{array}$ & $\stackrel{i}{i}$ & n & 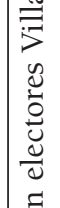 & 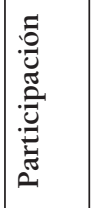 & $\begin{array}{l}n \\
\infty \\
\infty\end{array}$ & $\hat{0}$ & $\frac{0}{\infty}$ & $\stackrel{\infty}{\infty}$ & $\begin{array}{l}\mathfrak{n} \\
\stackrel{N}{N}\end{array}$ & $\stackrel{+}{\infty}$ & $\begin{array}{l}\infty \\
\hat{b}\end{array}$ & $\begin{array}{l}0 \\
\text { ti }\end{array}$ & $\infty$ \\
\hline 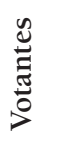 & 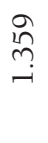 & $\begin{array}{l}\text { a } \\
\text { in } \\
i\end{array}$ & $\begin{array}{l}\vec{\infty} \\
0 \\
\dot{m}\end{array}$ & $\underset{⿱}{\stackrel{⿱}{+}}$ & $\overrightarrow{\dddot{r}}$ & 슨 & $\begin{array}{l}n \\
\mathfrak{f} \\
n \\
\dot{0} \\
\dot{f}\end{array}$ & 苟 & 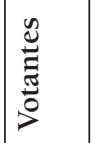 & 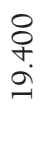 & $\underset{-}{\stackrel{\sim}{\sigma}}$ & $\stackrel{\sim}{\sim}$ & $\begin{array}{l}\stackrel{-}{\circ} \\
\stackrel{i}{i}\end{array}$ & $\begin{array}{l}\dot{1} \\
\stackrel{2}{-}\end{array}$ & $\underset{\sim}{\stackrel{q}{+}}$ & $\vec{a}$ & กี & $\begin{array}{l}\stackrel{n}{n} \\
\stackrel{N}{N}\end{array}$ \\
\hline 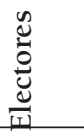 & 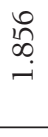 & $\begin{array}{l}0 \\
\infty \\
0 \\
\dot{m}\end{array}$ & $\begin{array}{l}\stackrel{\infty}{\sim} \\
\stackrel{+}{+}\end{array}$ & 。ి & 운 & ñ & 亲 & 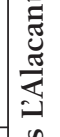 & 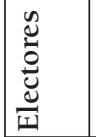 & $\begin{array}{l}\tilde{\delta} \\
\\
\end{array}$ & $\begin{array}{l}\overrightarrow{0} \\
\vec{\sim} \\
\text { i }\end{array}$ & ஓ & $\begin{array}{l}n \\
\stackrel{0}{0} \\
\stackrel{+}{i}\end{array}$ & 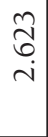 & $\begin{array}{c}\hat{\infty} \\
\stackrel{\infty}{-}\end{array}$ & $\hat{R}$ & ర్రి & $\begin{array}{l}q \\
m \\
\dot{m}\end{array}$ \\
\hline 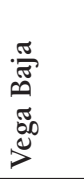 & 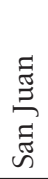 & 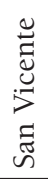 & $\tilde{\tilde{0}}$ & 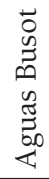 & $\begin{array}{l}\overrightarrow{0} \\
\text { के } \\
\tilde{a}\end{array}$ & 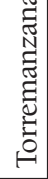 & 苛 & 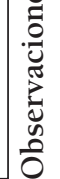 & 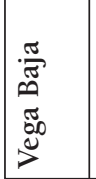 & $\frac{\hat{0}}{\dot{z}}$ & 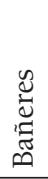 & 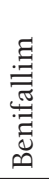 & 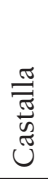 & $\vec{\theta}$ & $\bar{\Xi}$ & 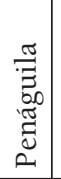 & $\tilde{\vec{F}}$ & 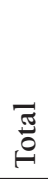 \\
\hline
\end{tabular}

Pasado y Memoria. Revista de Historia Contemporánea, 11, 2012, pp. 205-238 


\begin{tabular}{|c|c|c|c|c|c|c|c|c|c|c|c|c|c|c|c|c|c|}
\hline$\frac{n}{0}$ & 10 & 0 & 0 & 0 & 0 & 0 & 0 & 0 & 0 & 0 & 0 & 0 & 0 & 0 & 10 & 0 & 0 \\
\hline $\begin{array}{l}\stackrel{0}{\Xi} \\
\frac{\pi}{0}\end{array}$ & 0 & 0 & 0 & 0 & - & 0 & 0 & 0 & 0 & 0 & 0 & 0 & 0 & $\sim$ & 0 & 0 & 0 \\
\hline $\begin{array}{l}0 \\
0 \\
0 \\
0 \\
0\end{array}$ & $\begin{array}{l}0 \\
0\end{array}$ & O & $\begin{array}{l}0 \\
0\end{array}$ & $\stackrel{n}{\sim}$ & $\begin{array}{l}0 \\
0\end{array}$ & 0 & $\vec{m}$ & \begin{tabular}{l|}
0 \\
0
\end{tabular} & $\stackrel{0}{-i}$ & \begin{tabular}{l|}
0 \\
0
\end{tabular} & $\begin{array}{l}0 \\
0\end{array}$ & \begin{tabular}{l|}
0 \\
0
\end{tabular} & $\begin{array}{l}0 \\
0\end{array}$ & $\begin{array}{l}m \\
0\end{array}$ & $\overrightarrow{0}$ & $\tilde{O}$ & $\tilde{O}$ \\
\hline$\stackrel{n}{0}$ & $\stackrel{2}{2}$ & 0 & 0 & $\stackrel{2}{\sim}$ & 0 & 0 & পি & 0 & $n$ & $\sim$ & 0 & 0 & 0 & ৪ & $\sim$ & N & -1 \\
\hline 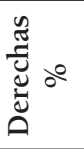 & \begin{tabular}{c|}
0 \\
$\infty$ \\
+
\end{tabular} & $\begin{array}{l}N \\
\infty \\
m\end{array}$ & $\begin{array}{l}0 \\
\text { in } \\
\text { in }\end{array}$ & $\stackrel{N}{N}$ & $\hat{\tilde{\nu}}$ & $\begin{array}{l}0 \\
\tilde{D}^{\circ}\end{array}$ & $\begin{array}{l}m \\
m \\
m\end{array}$ & $\begin{array}{l}1 \\
\infty \\
n \\
n\end{array}$ & $\begin{array}{c}0 \\
\infty \\
0\end{array}$ & \begin{tabular}{|l|}
\multirow{\sigma}{*}{} \\
+
\end{tabular} & $\begin{array}{l}\infty \\
i n \\
i n\end{array}$ & $\begin{array}{l}+ \\
\dot{0} \\
i n\end{array}$ & $\begin{array}{l}10 \\
\hat{6}\end{array}$ & $\begin{array}{l}0 \\
i \\
\text { in }\end{array}$ & $\begin{array}{l}+ \\
g \\
0\end{array}$ & $\hat{\sigma}$ & $\hat{a}$ \\
\hline 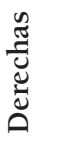 & \begin{tabular}{|l|} 
\\
$\delta$ \\
\\
$i$
\end{tabular} & $\underset{\leftarrow}{\stackrel{t}{f}}$ & $\begin{array}{l} \\
\text { 定 } \\
-1\end{array}$ & 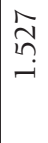 & $\tilde{\widetilde{F}}$ & $\begin{array}{l}0 \\
n \\
m\end{array}$ & 寺 & \begin{tabular}{|l|}
\multirow{+}{+}{} \\
$\stackrel{\sim}{\sim}$ \\
- \\
\end{tabular} & \begin{tabular}{|l|} 
\\
$\infty$ \\
$\infty$ \\
+ \\
+
\end{tabular} & 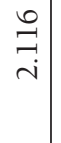 & $\tilde{\vartheta}$ & 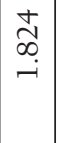 & 呆 & $\begin{array}{l}0 \\
i n \\
0 \\
i n \\
-1\end{array}$ & $\stackrel{\circ}{\exists}$ & $\begin{array}{l}\infty \\
\infty \\
\infty\end{array}$ & $\begin{array}{l}\infty \\
\stackrel{2}{1} \\
\text { in }\end{array}$ \\
\hline 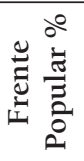 & $\frac{m}{n}$ & $\hat{\sigma}$ & $\begin{array}{l}0 \\
0 \\
+\end{array}$ & 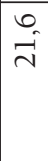 & $\dot{\sigma}^{+}$ & \begin{tabular}{l}
0 \\
\multirow{N}{*}{}
\end{tabular} & $\frac{0}{6}$ & \begin{tabular}{c|}
$\infty$ \\
$F$ \\
$F$
\end{tabular} & $\frac{0}{m}$ & $\begin{array}{l}n \\
\tilde{n}\end{array}$ & $\begin{array}{l}f \\
f\end{array}$ & \begin{tabular}{|c|}
0 \\
$\dot{q}$
\end{tabular} & $\begin{array}{l}n \\
0 \\
n \\
m\end{array}$ & $\begin{array}{l}2 \\
\text { 采 }\end{array}$ & $\hat{n}$ & $\begin{array}{l}\infty \\
0 \\
0\end{array}$ & $\begin{array}{l}0 \\
+\end{array}$ \\
\hline 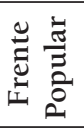 & 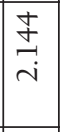 & $\underset{6}{\mathbb{N}}$ & 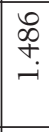 & 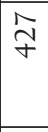 & ช̂ & 足 & $\overline{8}$ & \begin{tabular}{|l|} 
\\
$\infty$ \\
$\infty$
\end{tabular} & 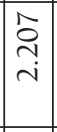 & $\begin{array}{c}J \\
\tilde{j} \\
\end{array}$ & $\underset{\infty}{+}$ & \begin{tabular}{l|}
$\infty$ \\
o \\
+⿱ \\
-1 \\
\end{tabular} & 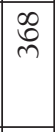 & $\begin{array}{l}m \\
\tilde{\sigma} \\
\dot{+} \\
\dot{+}\end{array}$ & \begin{tabular}{|l|}
$\infty$ \\
$\infty$ \\
$+\infty$
\end{tabular} & $t$ & $\stackrel{ \pm}{\sim}$ \\
\hline 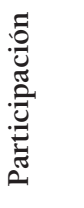 & $\begin{array}{l}m \\
i n\end{array}$ & $\overrightarrow{\hat{\sigma}}$ & $\hat{r}$ & $\frac{1}{N}$ & $\begin{array}{l}a \\
\dot{\theta}\end{array}$ & $\begin{array}{l}\sim \\
\stackrel{\infty}{\infty}\end{array}$ & $\begin{array}{l}0 \\
\infty \\
i n\end{array}$ & $\stackrel{-}{N}$ & $\begin{array}{l}0 \\
0 \\
1\end{array}$ & $\begin{array}{l}0 \\
N \\
N\end{array} \mid$ & $\hat{m}$ & $\begin{array}{l}2 \\
\tilde{8} \\
\infty\end{array}$ & $\begin{array}{l}0 \\
\infty \\
\infty \\
0\end{array}$ & $\frac{n}{N}$ & $\begin{array}{l}0 \\
8\end{array}$ & $\hat{\theta}$ & $\begin{array}{l}0 \\
8 \\
8\end{array}$ \\
\hline 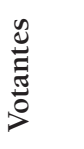 & 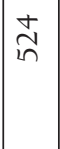 & $\hat{m}$ & \& & $\overrightarrow{\mathfrak{n}}$ & $\underset{-1}{+}$ & $\stackrel{\infty}{\infty}$ & $\stackrel{\overbrace{}}{\beth}$ & $\begin{array}{l}0 \\
\text { I } \\
\end{array}$ & $\begin{array}{l}2 n \\
\infty \\
\infty\end{array}$ & \begin{tabular}{l|}
$\infty$ \\
$i n$ \\
in
\end{tabular} & กี & to & 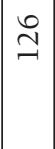 & $\begin{array}{l}\frac{m}{T} \\
\dot{m}\end{array}$ & 고 & $\stackrel{\infty}{=}$ & 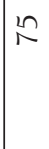 \\
\hline$\frac{0}{0}$ & ᄋ̊ & $\bar{\sim}$ & $\vec{n}$ & $\stackrel{n}{m}$ & 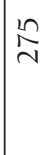 & $\frac{\ln }{\mathrm{N}}$ & $\stackrel{\circ}{\sim}$ & $\begin{array}{l}0 \\
\text { nn } \\
m\end{array}$ & 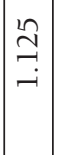 & $\stackrel{2}{1}$ & $\mathfrak{N}$ & 广ீ & $\stackrel{\infty}{\infty}$ & $\begin{array}{l}\infty \\
\underset{I}{1} \\
\infty \\
+\end{array}$ & 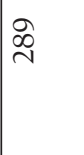 & 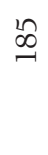 & $\stackrel{\sim}{\beth}$ \\
\hline 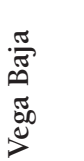 & 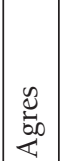 & 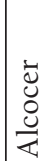 & $\begin{array}{l}\frac{\pi}{0} \\
0 \\
0 \\
0 \\
0 \\
\end{array}$ & $\frac{\pi}{\frac{\pi}{\pi}}$ & 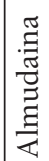 & 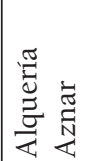 & $\begin{array}{l}\tilde{\Xi} \\
\tilde{0} \\
\tilde{0} \\
\tilde{\pi} \\
\tilde{n}\end{array}$ & 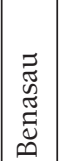 & 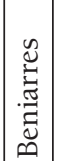 & 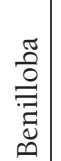 & 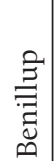 & 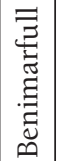 & 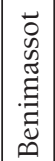 & 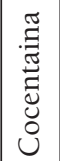 & 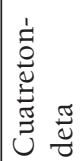 & $\begin{array}{l}\tilde{U} \\
\stackrel{U}{U} \\
\tilde{U} \\
\tilde{I}\end{array}$ & $\begin{array}{l}\widetilde{0} \\
0 \\
0 \\
\tilde{\Xi} \\
\tilde{I}\end{array}$ \\
\hline
\end{tabular}

Pasado y Memoria. Revista de Historia Contemporánea, 11, 2012, pp. 205-238 


\begin{tabular}{|c|c|c|c|c|c|c|c|c|}
\hline$\frac{n}{3}$ & 0 & 0 & 0 & 0 & 0 & 0 & 0 & 0 \\
\hline 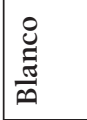 & 0 & 0 & 0 & 0 & 0 & 0 & 0 & $m$ \\
\hline $\begin{array}{l}0 \\
n \\
0 \\
0 \\
0\end{array}$ & Oे & $\stackrel{+}{\circ}$ & O & $\hat{\imath}$ & $\overrightarrow{0}$ & O & $\begin{array}{l}0 \\
0\end{array}$ & $\tilde{o}^{n}$ \\
\hline$\stackrel{n}{0}$ & 0 & $\lambda$ & 0 & Әे & $\infty$ & $\neg$ & 0 & 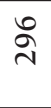 \\
\hline 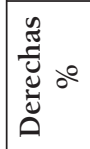 & $\begin{array}{l}\text { Na } \\
\text { mे }\end{array}$ & $\tilde{\sigma}$ & $\begin{array}{l}0 \\
\text { in }\end{array}$ & $\begin{array}{l}\infty \\
\infty \\
\infty\end{array}$ & $\begin{array}{l}0 \\
\infty \\
+\infty \\
+\end{array}$ & $\hat{n}$ & $\begin{array}{l}0 \\
\text { f́ }\end{array}$ & $\hat{n}$ \\
\hline 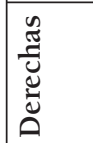 & $\begin{array}{l}\infty \\
\widetilde{\sigma}\end{array}$ & $\begin{array}{l}\stackrel{ }{\nearrow} \\
\stackrel{\sim}{-}\end{array}$ & $\begin{array}{l}\stackrel{+}{+} \\
\stackrel{n}{m}\end{array}$ & ñ & 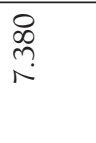 & 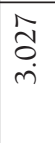 & 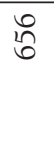 & $\begin{array}{l}\infty \\
\stackrel{\infty}{N} \\
\hat{n} \\
\hat{n}\end{array}$ \\
\hline 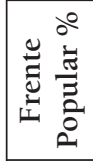 & $\begin{array}{l}\infty \\
8\end{array}$ & $\begin{array}{l}m \\
\infty^{n} \\
m\end{array}$ & $\begin{array}{l}\dot{q} \\
\dot{q}\end{array}$ & $\begin{array}{l}n \\
0 \\
0\end{array}$ & $\begin{array}{l}0 \\
\text { in }\end{array}$ & $\hat{\sigma}$ & $\begin{array}{l}\dot{m} \\
\tilde{m}\end{array}$ & $\begin{array}{l}1 \\
6 \\
f\end{array}$ \\
\hline 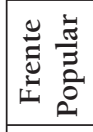 & $\underset{r}{\stackrel{+}{+}}$ & 垈 & $\begin{array}{l}\infty \\
\stackrel{\infty}{0} \\
\stackrel{m}{*}\end{array}$ & $\stackrel{8}{8}$ & ஓ. & $\begin{array}{l}\tilde{n} \\
\hat{\sigma} \\
i\end{array}$ & $\stackrel{8}{8}$ & 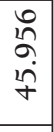 \\
\hline 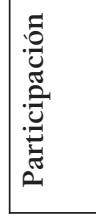 & $\begin{array}{l}10 \\
\infty^{\circ}\end{array}$ & $\begin{array}{l}1 n \\
\infty \\
\infty\end{array}$ & $\begin{array}{l}0 \\
\text { i } \\
\infty\end{array}$ & 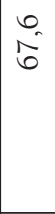 & $\begin{array}{l}+ \\
i \\
\infty\end{array}$ & $\stackrel{m}{\stackrel{m}{N}}$ & $\stackrel{+}{\tilde{\sigma}}$ & $\begin{array}{l}\dot{\sigma}_{n} \\
\stackrel{N}{2}\end{array}$ \\
\hline 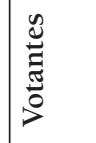 & 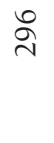 & $\underset{\sim}{\stackrel{\sim}{\sim}}$ & $\vec{\infty}$ & $\stackrel{\dddot{\jmath}}{\beth}$ & $\underset{+}{\stackrel{+}{+}}$ & $\stackrel{\circ}{1}$ & 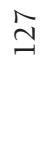 & 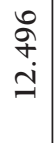 \\
\hline 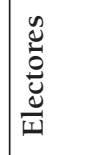 & $\underset{m}{N}$ & 六 & ? & $\underset{\infty}{\infty}$ & $\begin{array}{l}\infty \\
\stackrel{n}{n} \\
\stackrel{n}{i}\end{array}$ & ڤั & $\stackrel{\sim}{=}$ & $\begin{array}{l}\stackrel{0}{1} \\
\stackrel{0}{0}\end{array}$ \\
\hline 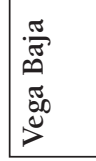 & 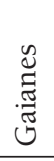 & 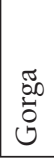 & 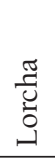 & 苞 & 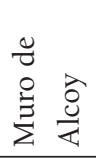 & $\begin{array}{l}\tilde{\Xi} \\
\frac{\tilde{\sigma}}{2} \\
\end{array}$ & 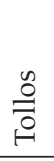 & 芫 \\
\hline
\end{tabular}

\begin{tabular}{|c|c|c|c|c|c|c|c|}
\hline$\frac{\stackrel{n}{E}}{z}$ & 0 & 0 & 0 & 0 & 0 & 0 & 0 \\
\hline $\begin{array}{l}\stackrel{8}{\Xi} \\
\frac{\pi}{\infty}\end{array}$ & 0 & 0 & 0 & 0 & 0 & 0 & 0 \\
\hline $\begin{array}{l}0 \\
0 \\
0 \\
0 \\
0\end{array}$ & $\begin{array}{l}0 \\
0\end{array}$ & $\overrightarrow{0}$ & $\overrightarrow{0}$ & $\begin{array}{l}0 \\
\sigma\end{array}$ & $\underset{\tau}{+}$ & $\begin{array}{l}0 \\
0\end{array}$ & 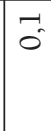 \\
\hline$\stackrel{\mathscr{\Xi}}{0}$ & 0 & + & $\lambda$ & ஃ & In & 0 & $m$ \\
\hline 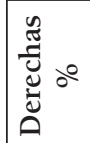 & $\begin{array}{l}n \\
\hat{n} \\
\tilde{m}\end{array}$ & $\begin{array}{l}m \\
\infty \\
i n\end{array}$ & $\begin{array}{l}0 \\
\text { in } \\
\text { in }\end{array}$ & $\begin{array}{l}0 \\
\hat{m} \\
m\end{array}$ & \begin{tabular}{|l|}
$n$ \\
$\hat{6}$ \\
0
\end{tabular} & $\begin{array}{l}n \hat{n} \\
\hat{n}\end{array}$ & $\hat{\tilde{q}}$ \\
\hline 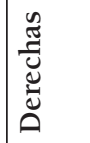 & $\begin{array}{l}\infty \\
\widetilde{\alpha}\end{array}$ & $\begin{array}{l}8 \\
\text { in } \\
i\end{array}$ & 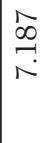 & $\stackrel{\infty}{\infty}$ & $\begin{array}{l}\hat{n} \\
\tilde{n} \\
\end{array}$ & $\begin{array}{l}\circ \\
\infty \\
0\end{array}$ & 孚 \\
\hline 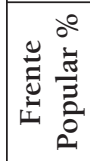 & $\begin{array}{l}\infty \\
8 \\
0\end{array}$ & $\frac{0}{F}$ & $\begin{array}{l}0 \\
6 \\
f\end{array}$ & 㫌 & $\vec{m}$ & \begin{tabular}{|l|}
10 \\
6 \\
+
\end{tabular} & 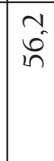 \\
\hline 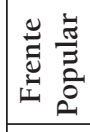 & 季 & $\underset{\sim}{\mathcal{T}}$ & 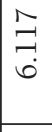 & 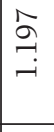 & $\begin{array}{l}\tilde{D} \\
\infty \\
m \\
m\end{array}$ & in & 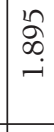 \\
\hline 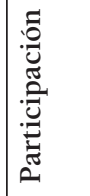 & $\begin{array}{l}\text { in } \\
\infty \\
1\end{array}$ & $\begin{array}{l}\sigma_{-} \\
\hat{\sigma}\end{array}$ & $\begin{array}{l}+ \\
6 \\
0\end{array}$ & $\begin{array}{l}0 \\
0\end{array}$ & $\mid \begin{array}{l}\infty \\
0 \\
0\end{array}$ & $\begin{array}{l}0 \\
10 \\
1\end{array}$ & $\stackrel{m}{N}$ \\
\hline 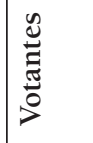 & ঐ & 志 & 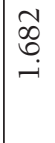 & $\begin{array}{l}\infty \\
\mathbb{N} \\
\sim\end{array}$ & $\begin{array}{l}\Omega \\
\mathcal{R} \\
n \\
-1\end{array}$ & ถે & $\underset{+}{\stackrel{+}{*}}$ \\
\hline 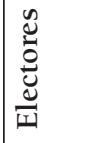 & $\frac{N}{N}$ & $\tilde{N}$ & $\begin{array}{l}0 \\
\text { in } \\
\text { i }\end{array}$ & ○ & $\begin{array}{c}\stackrel{a}{+} \\
\stackrel{\sigma}{-}\end{array}$ & $\underset{\sim}{\sim}$ & if \\
\hline 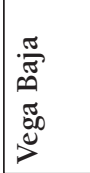 & 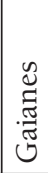 & 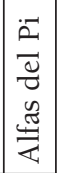 & $\stackrel{\Xi}{\mathscr{Z}}$ & 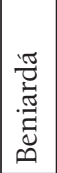 & 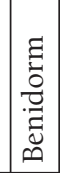 & 离 & 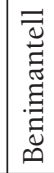 \\
\hline
\end{tabular}

Pasado y Memoria. Revista de Historia Contemporánea, 11, 2012, pp. 205-238 


\begin{tabular}{|c|c|c|c|c|c|c|c|c|c|c|c|c|c|c|c|}
\hline$\frac{n}{0}$ & 0 & 0 & 0 & 0 & 0 & 0 & 0 & 0 & 0 & 0 & & & 0 & 0 & 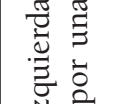 \\
\hline 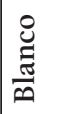 & 0 & 0 & - & 0 & 0 & 0 & 0 & 0 & 0 & 0 & & & 0 & - & 吾 \\
\hline $\begin{array}{l}0 \\
0 \\
n \\
0 \\
0 \\
0\end{array}$ & $\begin{array}{l}\text { in } \\
\text { in }\end{array}$ & $\begin{array}{l}0 \\
i\end{array}$ & $\hat{m}^{m}$ & $\hat{n}$ & ป̂ & m & in & $\hat{m}$ & $\hat{n}$ & 0 & & & $\begin{array}{c}n \\
0\end{array}$ & N & 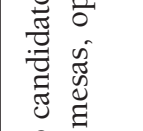 \\
\hline 苞 & $\infty$ & 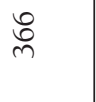 & $a$ & $\stackrel{\infty}{\infty}$ & in & $\vec{\sim}$ & $\stackrel{0}{-1}$ & 合 & $\stackrel{ }{\sim}$ & $\stackrel{20}{\sim}$ & & & 字 & $\stackrel{n}{\stackrel{n}{+}}$ & 䒕 \\
\hline 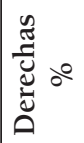 & $\begin{array}{l}\infty \\
\delta^{\infty} \\
\text { in }\end{array}$ & $\begin{array}{l}{ }_{1} \\
\infty \\
1\end{array}$ & $\frac{n}{n}$ & $\begin{array}{l}m \\
\stackrel{m}{n}\end{array}$ & $\frac{0}{i}$ & $\hat{\partial}$ & $\begin{array}{l}\infty \\
8 \\
8\end{array}$ & $\begin{array}{l}0 \\
0 \\
+\end{array}$ & à & $\begin{array}{l}0 \\
\text { in } \\
\text { in }\end{array}$ & & & $\begin{array}{l}\infty \\
0_{1}\end{array}$ & ñ & 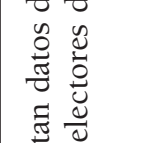 \\
\hline 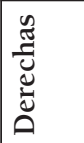 & $\frac{a}{\infty}$ & $\begin{array}{l}\infty \\
\infty \\
+\infty \\
\infty\end{array}$ & $\stackrel{\text { mे }}{\dot{r}}$ & $\begin{array}{l}+ \\
\infty \\
\infty \\
i\end{array}$ & $\begin{array}{l}0 \\
\infty \\
\infty\end{array}$ & 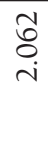 & $\begin{array}{l}\underset{+}{+} \\
\infty \\
-1 \\
-1\end{array}$ & ஜே & $\begin{array}{l}\hat{n} \\
\text { ñ } \\
\dot{+}\end{array}$ & $\begin{array}{l}0 \\
8 \\
m\end{array}$ & & & $\begin{array}{l}8 \\
\stackrel{8}{2} \\
\stackrel{+}{ \pm}\end{array}$ & $\begin{array}{l}\text { in } \\
\text { in } \\
\text { to }\end{array}$ & $\begin{array}{ll}0 & 0 \\
0 & 0 \\
0 & 0 \\
0 & 0 \\
0\end{array}$ \\
\hline 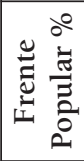 & $\hat{r}$ & $\begin{array}{l}a \\
\infty \\
m\end{array}$ & $\stackrel{\overrightarrow{0}}{\stackrel{\infty}{+}}$ & $\stackrel{\mathcal{N}}{f}$ & $\begin{array}{l}\infty \\
0^{\circ} \\
m\end{array}$ & $\begin{array}{l}\infty \\
8 \\
\delta\end{array}$ & $\begin{array}{l}N \\
\infty \\
m\end{array}$ & $\begin{array}{l}\text { ma } \\
\text { in }\end{array}$ & $\begin{array}{c}0 \\
\infty \\
+\infty\end{array}$ & $\begin{array}{l}0 \\
\tilde{y}\end{array}$ & & & $\begin{array}{l}0 \\
a \\
g\end{array}$ & $\begin{array}{l}n \\
\hat{o}^{\circ}\end{array}$ & 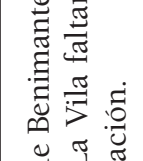 \\
\hline 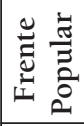 & ก) & $\begin{array}{l}\stackrel{+}{\mathfrak{r}} \\
\stackrel{+}{i}\end{array}$ & $\stackrel{+}{\stackrel{+}{m}}$ & $\underset{\stackrel{+}{+}}{\stackrel{+}{i}}$ & 志 & $\begin{array}{l}\infty \\
\infty \\
\infty \\
+\end{array}$ & $\begin{array}{l}8 \\
0 \\
-1 \\
-1\end{array}$ & 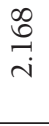 & $\begin{array}{l}8 \\
\stackrel{0}{0} \\
\text { m? }\end{array}$ & $\begin{array}{l}0 \\
7 \\
7 \\
2\end{array}$ & & & 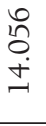 & 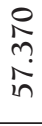 & 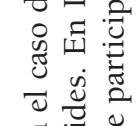 \\
\hline 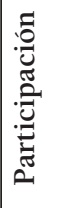 & $\begin{array}{l}\infty \\
\stackrel{n}{f}\end{array}$ & $\stackrel{+}{r}$ & $\begin{array}{l}0 \\
N^{n}\end{array}$ & $\hat{\sigma}$ & $\begin{array}{l}0 \\
i\end{array}$ & $\overrightarrow{0}$ & $\vec{n}$ & $\hat{8}$ & $\stackrel{+}{n}$ & $\begin{array}{l}10 \\
\infty \\
0\end{array}$ & & & $\frac{a}{b}$ & $\begin{array}{l}m \\
\infty \\
\infty\end{array}$ & 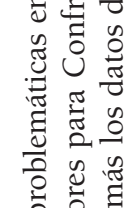 \\
\hline 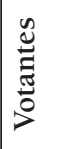 & $\stackrel{0}{\sim}$ & $\begin{array}{l}0 \\
\stackrel{0}{2} \\
-1\end{array}$ & $\stackrel{n}{n}$ & $\begin{array}{l}n \\
\infty \\
1\end{array}$ & 욤 & $\vec{\varnothing}$ & $\frac{n}{n}$ & $\stackrel{\infty}{n}$ & $\stackrel{\infty}{\stackrel{\infty}{\rightleftharpoons}}$ & $\tilde{8}$ & & & $\begin{array}{l}n \\
n \\
n \\
n\end{array}$ & 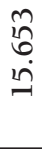 & 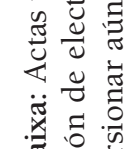 \\
\hline 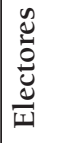 & $\underset{⿱}{+}$ & $\begin{array}{l}8 \\
\text { in } \\
\text { i }\end{array}$ & ஓ & 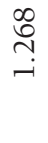 & $\stackrel{m}{\sim}$ & 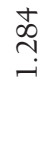 & $\frac{m}{n}$ & $\begin{array}{l}1 \\
\infty \\
\infty\end{array}$ & in & $\frac{0}{0}$ & & & $\begin{array}{l}\infty \\
0 \\
\text { Nִ } \\
\text { in }\end{array}$ & 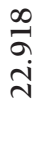 & 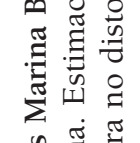 \\
\hline 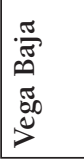 & $\begin{array}{l}\frac{\pi}{3} \\
\frac{3}{0} \\
0 \\
\end{array}$ & 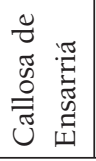 & 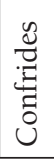 & 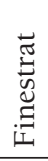 & $\frac{3}{\frac{3}{\pi}}$ & 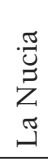 & 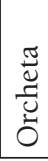 & $\begin{array}{l}\frac{0}{0} \\
0 \\
2\end{array}$ & 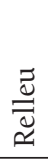 & $\stackrel{\pi}{=}$ & & & 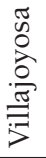 & 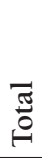 & 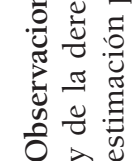 \\
\hline
\end{tabular}

Pasado y Memoria. Revista de Historia Contemporánea, 11, 2012, pp. 205-238 


\begin{tabular}{|c|c|c|c|c|c|c|c|c|c|c|c|c|c|c|c|c|c|c|c|c|}
\hline$\frac{n}{3}$ & 0 & 0 & 0 & 0 & 0 & 0 & 0 & 0 & 0 & 0 & 0 & 0 & 0 & 0 & 0 & 0 & 0 & 0 & 0 & 0 \\
\hline 范 & 0 & 0 & 0 & 0 & 0 & 0 & 0 & 0 & 0 & 0 & 0 & 0 & 0 & 0 & 0 & 0 & + & 0 & 0 & 0 \\
\hline $\begin{array}{l}0 \\
0 \\
0 \\
0 \\
0 \\
0\end{array}$ & 0 & $O_{0}^{\circ}$ & 京 & O & $\begin{array}{l}0 \\
0\end{array}$ & \begin{tabular}{|l|} 
\\
0
\end{tabular} & $m$ & $\begin{array}{l}0 \\
0\end{array}$ & $\begin{array}{l}n \\
\tilde{o}\end{array}$ & $\begin{array}{l}0 \\
0\end{array}$ & $\begin{array}{l}0 \\
-1\end{array}$ & $\dot{\sigma}$ & $\overrightarrow{0}$ & $\hat{o}$ & \begin{tabular}{|l|} 
\\
\end{tabular} & $\begin{array}{l}0 \\
0\end{array}$ & $\begin{array}{l}0 \\
0\end{array}$ & $O^{\circ}$ & $\tilde{m}$ & $\overrightarrow{0}$ \\
\hline$\stackrel{n}{0}$ & 0 & 0 & $\frac{0}{\sim}$ & 0 & 0 & 0 & $\hat{\widetilde{\sigma}}$ & 0 & $\exists$ & 0 & $\tilde{\sigma}$ & $g$ & $\infty$ & in & 0 & 0 & 0 & $\mathrm{~N}$ & 웅 & $m$ \\
\hline 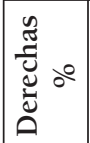 & ดั & $\begin{array}{l}t_{n} \\
\text { á }\end{array}$ & $\begin{array}{l}\infty \\
\infty \\
\infty\end{array}$ & $\stackrel{\dot{m}}{N}$ & $\begin{array}{l}0 \\
i \\
i\end{array}$ & $\begin{array}{ll}\overrightarrow{1} \\
\infty\end{array}$ & \begin{tabular}{|l|}
$n$ \\
$\sim$ \\
0
\end{tabular} & $\begin{array}{l}\sim \\
10 \\
N\end{array}$ & $\begin{array}{l}n \\
n \\
N\end{array}$ & $\hat{n}$ & \begin{tabular}{|l|}
0 \\
0 \\
$m$
\end{tabular} & $\begin{array}{l}0 \\
\hat{m}\end{array}$ & \begin{tabular}{l|}
$m$ \\
$\infty$ \\
$\infty$ \\
$\infty$
\end{tabular} & $\stackrel{9}{F}$ & $\begin{array}{l}N \\
\\
-1\end{array}$ & $\tilde{N}$ & $\begin{array}{l}\infty \\
\infty \\
\infty \\
0\end{array}$ & $\begin{array}{l}1 \\
0 \\
i \\
\end{array}$ & $\hat{N}$ & \begin{tabular}{|l|}
10 \\
$\infty$ \\
10
\end{tabular} \\
\hline 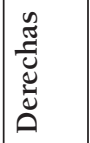 & $\begin{array}{l}\infty \\
o \\
+ \\
\dot{c}\end{array}$ & 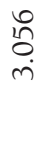 & $\begin{array}{l}\tilde{N} \\
\hat{\sim} \\
\sim\end{array}$ & $\begin{array}{l}\stackrel{\infty}{+} \\
\stackrel{+}{\sim}\end{array}$ & $\begin{array}{l}\underset{\infty}{ \pm} \\
\underset{-}{+}\end{array}$ & $\begin{array}{l}\mathcal{N} \\
\\
-i\end{array}$ & \begin{tabular}{|l|} 
\\
$\infty$ \\
$\infty$ \\
$\infty$ \\
\end{tabular} & \begin{tabular}{|c|}
+ \\
$\infty$ \\
0 \\
0 \\
0
\end{tabular} & \begin{tabular}{l|}
$\sim$ \\
$\infty$ \\
$i n$ \\
$\sim$ \\
$\sim$
\end{tabular} & $\begin{array}{l}\text { J } \\
\text { i } \\
\text { in }\end{array}$ & $\begin{array}{c}\mathfrak{N} \\
\mathfrak{n} \\
\mathfrak{d} \\
-1\end{array}$ & 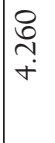 & $\begin{array}{l}\mathbb{N} \\
0 \\
0 \\
0\end{array}$ & $\begin{array}{l}\stackrel{6}{o} \\
\stackrel{1}{r}\end{array}$ & $\tilde{\widehat{\sigma}}$ & $\stackrel{\infty}{\circ}$ & $\begin{array}{l}\stackrel{\circ}{\circ} \\
\stackrel{2}{-}\end{array}$ & $\begin{array}{l}\infty \\
i n \\
\\
0\end{array}$ & ঐે & $\begin{array}{l}\infty \\
\stackrel{2}{\sim} \\
\stackrel{\sim}{i}\end{array}$ \\
\hline 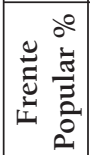 & $\stackrel{\sim}{n}$ & $\begin{array}{l}0 \\
i\end{array}$ & $\begin{array}{l}\infty \\
i n\end{array}$ & $\begin{array}{l}0 \\
\stackrel{0}{0} \\
\stackrel{0}{*}\end{array}$ & \begin{tabular}{l}
$\sigma_{n}$ \\
\multirow{N}{*}{}
\end{tabular} & \begin{tabular}{l|} 
\\
$\infty$ \\
-1
\end{tabular} & $m$ & $\begin{array}{l}\infty \\
\dot{\sim}\end{array}$ & $\begin{array}{l}n \\
\tilde{b} \\
2\end{array}$ & $\hat{\tilde{N}}$ & $\begin{array}{l}a \\
\hat{b} \\
0\end{array}$ & $\begin{array}{l}0 \\
8 \\
8\end{array}$ & $\stackrel{n}{\approx}=$ & $\begin{array}{l}a_{1} \\
\text { in }\end{array}$ & \begin{tabular}{c|}
$\infty$ \\
$i$ \\
$\infty$
\end{tabular} & $\begin{array}{l}n \\
\\
\end{array}$ & $\stackrel{0}{m}$ & $\begin{array}{l}n \\
\hat{N}\end{array}$ & $\begin{array}{l}0 \\
\stackrel{0}{0}\end{array}$ & $\begin{array}{l}+ \\
F\end{array}$ \\
\hline 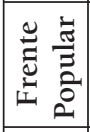 & $\underset{J}{\exists}$ & $\infty$ & 8 & $\begin{array}{l}\infty \\
\infty \\
\infty\end{array}$ & $\begin{array}{l}\infty \\
\infty \\
0 \\
0\end{array}$ & \begin{tabular}{|l|}
8 \\
\end{tabular} & $\begin{array}{l}\stackrel{M}{N} \\
\stackrel{+}{+}\end{array}$ & $\begin{array}{l}\stackrel{O}{+} \\
\stackrel{1}{\sim} \\
\text { in }\end{array}$ & $\hat{n}$ & \%ั & 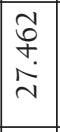 & $\begin{array}{l}\hat{\sigma} \\
\overrightarrow{0} \\
0\end{array}$ & $\mid \begin{array}{c}\mathbb{N} \\
\infty\end{array}$ & $\begin{array}{l}\tilde{N} \\
\stackrel{0}{0} \\
-\end{array}$ & \begin{tabular}{|l|} 
\\
8 \\
\\
$\dot{m}$
\end{tabular} & 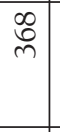 & $\begin{array}{l}\infty \\
\mathbb{0} \\
0\end{array}$ & $\begin{array}{l}\infty \\
\stackrel{\infty}{\sim} \\
\sim\end{array}$ & $\vec{\infty}$ & $\begin{array}{l}n=0 \\
n \\
n\end{array}$ \\
\hline 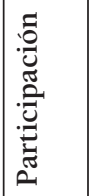 & $\begin{array}{l}0 \\
0 \\
2\end{array}$ & $\begin{array}{l}\text { a } \\
\text { in }\end{array}$ & $\overrightarrow{8}$ & $\begin{array}{l}\text { a } \\
\text { N }\end{array}$ & $\hat{0}$ & $\left|\begin{array}{l}0 \\
\infty \\
\infty\end{array}\right|$ & $\begin{array}{l}t_{0} \\
0\end{array}$ & $\begin{array}{l}r \\
\tilde{a}\end{array}$ & $\frac{n}{m}$ & $\begin{array}{l}+ \\
\dot{f}\end{array}$ & $\begin{array}{l}n \\
0 \\
0\end{array}$ & $\begin{array}{l}\forall \\
i n \\
\text { in }\end{array}$ & $\begin{array}{l}t_{n} \\
\text { in }\end{array}$ & $\begin{array}{c}\text { N } \\
\text { in }\end{array}$ & $\begin{array}{c}0 \\
n\end{array}$ & 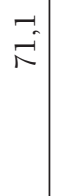 & $\begin{array}{l}0 \\
\hat{n}\end{array}$ & $\begin{array}{l}+ \\
\stackrel{0}{0} \\
\wp\end{array}$ & $\begin{array}{l}0 \\
\text { o }\end{array}$ & $\begin{array}{l}2 \\
\stackrel{+}{N}\end{array}$ \\
\hline 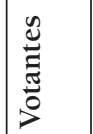 & $\underset{F}{F}$ & ڤે & 年 & $\frac{1}{\gamma}$ & $\frac{n}{m}$ & 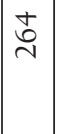 & $\begin{array}{l}\Omega \\
\stackrel{n}{r} \\
-\end{array}$ & 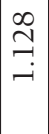 & $\underset{f}{J}$ & $\stackrel{\mathscr{2}}{\stackrel{7}{7}}$ & $\begin{array}{l}m \\
\stackrel{n}{1} \\
\dot{u}\end{array}$ & $\underset{\sim}{\stackrel{7}{7}}$ & m & 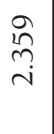 & $\mid \begin{array}{l}n \\
\tilde{f}\end{array}$ & $\hat{\sigma}$ & $\stackrel{+}{\stackrel{+}{\sim}}$ & 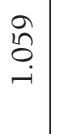 & ô & 索 \\
\hline 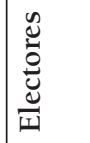 & $\begin{array}{l}\infty \\
i n \\
i n\end{array}$ & 힝 & 告 & 识 & in & $\begin{array}{l}\infty \\
\stackrel{\searrow}{\searrow}\end{array}$ & $\begin{array}{l}\hat{\infty} \\
\infty \\
m \\
\dot{m}\end{array}$ & 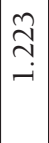 & 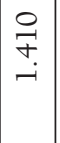 & $\frac{10}{a}$ & $\mid \begin{array}{l}\not \\
\infty \\
\sim \\
1\end{array}$ & $\begin{array}{l}\infty \\
\stackrel{\infty}{1} \\
\\
i\end{array}$ & 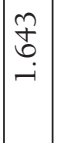 & $\underset{+}{\underset{\leftarrow}{\Xi}}$ & $\begin{array}{l}\hat{\alpha} \\
\infty \\
\dot{q}\end{array}$ & $\tilde{n}$ & $\vec{n}$ & $\begin{array}{l}0 \\
\infty \\
\infty \\
\end{array}$ & ஜे & ڤ్ర \\
\hline 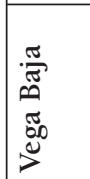 & $\begin{array}{c}\frac{\pi}{0} \\
\frac{3}{3} \\
\frac{5}{8}\end{array}$ & $\frac{\frac{i \pi}{\pi}}{\frac{\pi}{\pi}}$ & 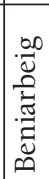 & 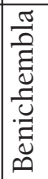 & 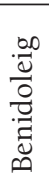 & 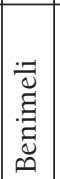 & 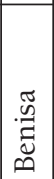 & 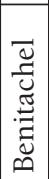 & $\frac{\tilde{\Xi}}{\tilde{J}}$ & 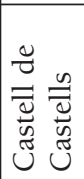 & 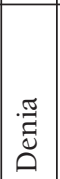 & \begin{tabular}{|l|}
0 \\
0 \\
0 \\
0 \\
0 \\
0 \\
$\tilde{3}$ \\
$\tilde{\Xi}$ \\
$ن$
\end{tabular} & 哠 & 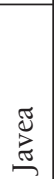 & 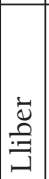 & 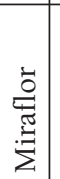 & $\stackrel{\frac{\pi}{\Xi}}{\Xi}$ & 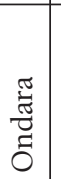 & $\begin{array}{l}\frac{\pi}{0} \\
\frac{0}{0}\end{array}$ & 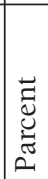 \\
\hline
\end{tabular}

Pasado y Memoria. Revista de Historia Contemporánea, 11, 2012, pp. 205-238 


\begin{tabular}{|c|c|c|c|c|c|c|c|c|c|c|c|c|c|c|c|c|}
\hline$\frac{n}{o}$ & 0 & 10 & 0 & 10 & 0 & 0 & 0 & 0 & 0 & 0 & 0 & 0 & 0 & 0 & 10 & 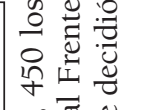 \\
\hline $\begin{array}{l}\mathscr{0} \\
\frac{\pi}{\pi} \\
\end{array}$ & 0 & 0 & 0 & 0 & 0 & 0 & 0 & 0 & 0 & 0 & 0 & N & 0 & 0 & 0 & 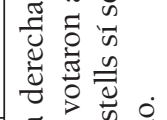 \\
\hline \begin{tabular}{|l|}
0 \\
0 \\
0 \\
0 \\
0
\end{tabular} & $\begin{array}{l}\sim \\
0 \\
0\end{array}$ & $\overrightarrow{0}$ & $\sigma_{0}$ & 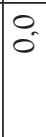 & $\begin{array}{l}0 \\
0\end{array}$ & \begin{tabular}{l|} 
\\
0
\end{tabular} & $\overrightarrow{0}$ & 约 & $\begin{array}{l}0 \\
0\end{array}$ & $\begin{array}{l}0 \\
0\end{array}$ & 0 & $\begin{array}{l}0 \\
0\end{array}$ & $\begin{array}{l}0 \\
\text { in }\end{array}$ & $0^{\circ}$ & 二 & 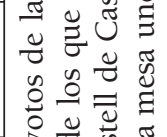 \\
\hline : & $\hat{m}$ & $\grave{\sim}$ & 으 & 0 & 0 & 0 & -1 & $\begin{array}{l}\infty \\
\text { in }\end{array}$ & 0 & 0 & 0 & - & $\stackrel{\mathscr{\Omega}}{\sim}$ & 0 & $\begin{array}{l}0 \\
1 \\
2 \\
i\end{array}$ & 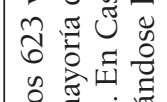 \\
\hline 胥 & $\vec{N}$ & \begin{tabular}{|c|} 
\\
$\infty$ \\
$0^{\circ}$
\end{tabular} & $\begin{array}{l}m \\
\hat{a}\end{array}$ & $\begin{array}{l}0 \\
\text { in }\end{array}$ & $\begin{array}{l}+ \\
\dot{\infty}\end{array}$ & $\begin{array}{l}t \\
a \\
q\end{array}$ & $\begin{array}{l}n \\
2 \\
R\end{array}$ & $\stackrel{m}{r}$ & $\begin{array}{l}\hat{\sigma} \\
\hat{\infty}\end{array}$ & $\hat{n}$ & $\begin{array}{l}\infty \\
\text { in } \\
\text { in }\end{array}$ & $\begin{array}{l}0 \\
8 \\
0\end{array}$ & $\begin{array}{l}\infty \\
\infty \\
\infty\end{array}$ & I & in & 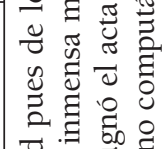 \\
\hline 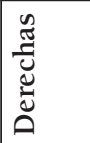 & $\begin{array}{ll}\infty \\
\infty \\
\sim \\
\sim \\
-1 \\
-1 \\
\end{array}$ & \begin{tabular}{|l|} 
\\
$\infty$ \\
0 \\
$\dot{v}$ \\
$\sim$
\end{tabular} & $\begin{array}{l}\hat{\sigma} \\
\dot{b} \\
\text { i }\end{array}$ & $\begin{array}{l}\text { on } \\
\text { m }\end{array}$ & 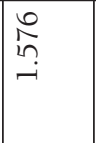 & 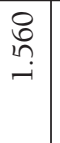 & 竎 & $\begin{array}{l}\stackrel{0}{\circ} \\
\stackrel{\leftrightarrow}{0} \\
\dot{0}\end{array}$ & 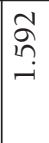 & 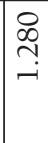 & 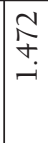 & $\begin{array}{l}\hat{n} \\
\hat{\alpha} \\
\dot{\gamma}\end{array}$ & $\begin{array}{l}0 \\
n \\
n \\
n\end{array}$ & $\begin{array}{l}q \\
b \\
\text { m }\end{array}$ & $\begin{array}{l}0 \\
1 \\
0 \\
0\end{array}$ & 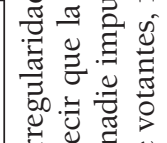 \\
\hline 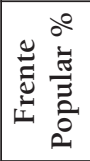 & \begin{tabular}{|l|}
$\hat{\imath}$ \\
$\hat{d}$
\end{tabular} & $\begin{array}{l}0 \\
\text { in }\end{array}$ & $\hat{m}$ & $\begin{array}{c}0 \\
\infty \\
+ \\
+\end{array}$ & $\begin{array}{l}0 \\
0 \\
0\end{array}$ & \begin{tabular}{l|}
0 \\
0 \\
$i n$
\end{tabular} & $\begin{array}{l}\infty \\
\text { ○ }\end{array}$ & ก̂ & 点 & $\begin{array}{l}n \\
0 \\
0\end{array}$ & $\begin{array}{l}\tilde{y} \\
\tilde{a}\end{array}$ & $\begin{array}{l}\dot{r} \\
\dot{m}\end{array}$ & $\begin{array}{l}10 \\
\text { in }\end{array}$ & $\begin{array}{l}m \\
\text { in } \\
m\end{array}$ & $\infty$ & 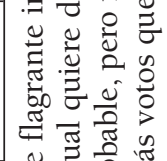 \\
\hline 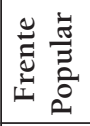 & 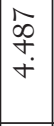 & $\begin{array}{l}2 \\
12 \\
\infty \\
0 \\
0\end{array}$ & t & กี & $\begin{array}{l}+ \\
\infty \\
m\end{array}$ & $\begin{array}{l}8 \\
8 \\
8 \\
-1 \\
\end{array}$ & $\begin{array}{l}+ \\
\infty \\
m\end{array}$ & $\begin{array}{l}0 \\
8 \\
\delta \\
\text { ij }\end{array}$ & $\begin{array}{l}\infty \\
\text { ñ }\end{array}$ & $\stackrel{\mathcal{I}}{=}$ & $\stackrel{\underset{t}{t}}{\sim}$ & $\begin{array}{l}8 \\
\stackrel{0}{1} \\
\stackrel{1}{i}\end{array}$ & 8 & $\begin{array}{l}\infty \\
\infty \\
a \\
-1\end{array}$ & \& & 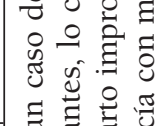 \\
\hline 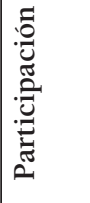 & $\begin{array}{l}1 \\
8 \\
8 \\
8\end{array}$ & $\begin{array}{l}\infty \\
8 \\
8\end{array}$ & $\begin{array}{l}1 \\
\infty \\
\infty\end{array}$ & $\begin{array}{l}m \\
\infty \\
\infty\end{array}$ & $\begin{array}{l}\infty \\
\text { co }\end{array}$ & $\begin{array}{l}\infty \\
\infty \\
\infty\end{array} \mid$ & 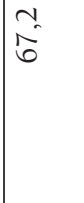 & $\vec{n}$ & बे & \begin{tabular}{l}
+ \\
\multirow{\infty}{*}{}
\end{tabular} & $\stackrel{n}{i}$ & $\begin{array}{l}0 \\
\hat{0}\end{array}$ & $\begin{array}{l}0 \\
\infty \\
i n\end{array}$ & $\hat{n}$ & t & 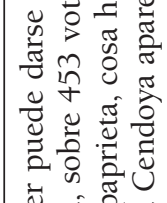 \\
\hline 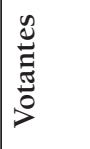 & $\begin{array}{l}o \\
\cdots \\
\vec{i} \\
i\end{array}$ & $\underset{ }{\stackrel{1}{\sim}}$ & o & $\stackrel{n}{\sim}$ & $\stackrel{0}{\sim}$ & भू & $\vec{\sim}$ & 국 & 온 & ঐे & $\hat{b}$ & $\begin{array}{l}\mathscr{1} \\
\infty \\
\infty\end{array}$ & in & $\frac{0}{1}$ & 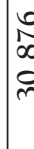 & 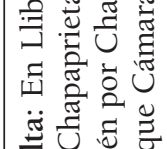 \\
\hline 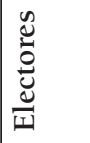 & $\mid \begin{array}{l}\infty \\
\stackrel{2}{\cdots} \\
m\end{array}$ & 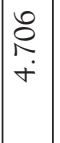 & হे & ৪্ণ & స̌ & $\begin{array}{l}\stackrel{i}{f} \\
\stackrel{1}{f}\end{array}$ & 吉 & : & d্ণ & $\hat{n}$ & in & مิ & ڤn & $\stackrel{m}{n}$ & 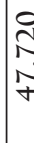 & 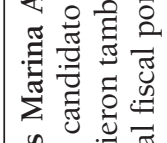 \\
\hline 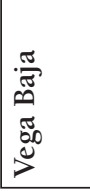 & 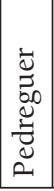 & $\mid$\begin{tabular}{l|}
0 \\
8 \\
0 \\
0
\end{tabular} & 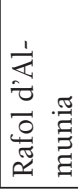 & \begin{tabular}{|l}
$\tilde{\sigma}$ \\
$\tilde{\sigma}$ \\
$\tilde{n}$
\end{tabular} & 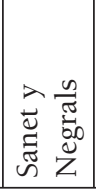 & $\begin{array}{l}: \frac{\sigma}{\vec{Z}} \\
\tilde{\omega} \\
\end{array}$ & 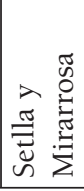 & $\frac{\frac{\pi}{3}}{\frac{\pi}{J}}$ & $\begin{array}{l}n \\
0 \\
\Xi \\
0 \\
0 \\
0\end{array}$ & 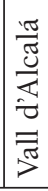 & 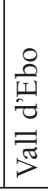 & 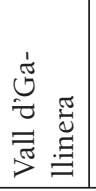 & 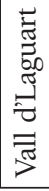 & 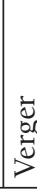 & & 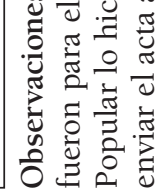 \\
\hline
\end{tabular}

Pasado y Memoria. Revista de Historia Contemporánea, 11, 2012, pp. 205-238 